\title{
Developmental Idealism and a Half Century of Family Attitude Trends in the United States
}

\author{
Forthcoming in Sociology of Development \\ August 15, 2022 \\ Keera Allendorf
Indiana University
kallendo@indiana.edu \\ Linda Young-DeMarco \\ University of Michigan \\ Arland Thornton \\ University of Michigan
}

\begin{abstract}
This paper examines a half century of trends in family attitudes and beliefs in the United States, including attitudes towards gender, marriage, childbearing, cohabitation, sex outside marriage, divorce, and same-sex relations. These trends are viewed through the lens of developmental idealism. We also describe how the developmental idealism framework applies to Western contexts generally and the United States specifically. We trace family attitudes from the 1960s through 2018 using four data sources: Intergenerational Panel Study of Parents and Children, Monitoring the Future, General Social Survey, and International Social Science Project. We find profound and largely consistent changes in Americans' attitudes. We argue these changes can be understood as the expansion of developmental idealism in the United States. Americans increasingly endorsed family attributes long understood as modern under developmental idealism, as well as attributes more recently viewed as modern through extensions of freedom and equality. At the same time, sizable majorities remained committed to marriage and having children. While Americans increasingly supported all individuals' freedom to choose among a diversity of family behaviors, most continued to view marriage and children favorably in their own lives.
\end{abstract}




\section{Developmental Idealism and a Half Century of Family Attitude Trends in the United States}

We examine trends in family attitudes and beliefs in the United States during the last half century, from the 1960s through the 2010s. The attitudes and beliefs we consider pertain to marriage, childbearing, divorce, cohabitation, gender, and same-sex relations, as well as heterosexual premarital and extramarital sex. We document these trends using four different large-scale, longitudinal surveys. Our empirical contribution lies in uniting broad substantive coverage with extended temporal coverage. Recent studies assessing ideational trends in the United States through the 2000s focus on single aspects of the family, such as same-sex relations (Andersen and Fetner 2008, Baunach 2011, Rosenfeld 2017) or gender (Cotter, Hermsen and Vanneman 2011, Pepin and Cotter 2018, Shu and Meagher 2018). We complement such in-depth studies by examining changes in attitudes and beliefs about many family aspects simultaneously. This approach allows us to identify broad patterns that hold across family attributes. Two earlier studies took this approach in examining an array of family attitudes from the 1960s to the 1990s (Thornton 1989, Thornton and Young-DeMarco 2001). We extend these earlier broad-based studies by adding two decades of data and tracking trends up through 2018.

We view these long-term trends in family attitudes in the United States through the lens of the developmental idealism framework (Allendorf and Thornton 2015, Thornton 2001, Thornton 2005, Thornton, Dorius and Swindle 2015, Thornton and Xie 2016). This application of a developmental idealism framework to the United States also comprises a contribution. The original formulation of the framework stressed the importance of developmental idealism for societies around the world (Thornton 2005). Subsequent applications of the framework have been primarily limited to settings outside Northwestern Europe and its diaspora in North America and Oceania, however, with the implication that it may apply largely, or even exclusively, to non-Western contexts. As described by Thornton (2005) and reiterated briefly 
below, developmental idealism does operate somewhat differently in Western societies, but is no less relevant. We argue the half century of trends in family attitudes we document can be understood as an expansion of developmental idealism in the United States.

We recognize these ideational trends could be framed through other theoretical frameworks, including socio-economic structural frameworks (Coleman 1990: Chapter 22, Giddens 1991, Goode 1963) and second demographic transition theory (Lesthaeghe 2010, Van de Kaa 1987). We do not compare the developmental idealism perspective to these other approaches, nor offer it as an all-encompassing alternative explanation of family change. Assessing the relative merits of the respective frameworks would require a far more comparative and expansive paper than we present here. Instead, we suggest changes in family attitudes and behavior do not share one common cause and no single theory accounts for the myriad changes that have occurred across the globe (Cherlin 2012, Mason 1997, Zaidi and Morgan 2017). We present developmental idealism as one more tool in our theoretical toolkit that powerfully enriches our theoretical apparatus for understanding changes in family attitudes and behavior worldwide.

This developmental idealism framework consists of both culture and theory components. Developmental idealism culture is a network of values and beliefs that provide an understanding of how the world works and how to live in that world (Thornton, Dorius and Swindle 2015). Among other things, this culture categorizes some family behaviors as modern and others as traditional, identifies modern behaviors as better than traditional ones, and positions freedom, equality, and consent as fundamental values (Thornton 2001, Thornton 2005, Thornton, Dorius and Swindle 2015). Other developmental idealism beliefs indicate societies naturally develop, or 
progress, over time and that modern family behaviors are causes and consequences of that progress.

Developmental idealism theory argues the beliefs and values comprising developmental idealism culture spread around the world and influenced family behavior by motivating individuals to adopt behaviors identified as good and modern (e.g. Allendorf and Thornton 2015, Thornton et al. 2012b, Thornton and Xie 2016). As developmental idealism culture spread, it encountered other systems of cultural values, with tension, resistance, rejection, and conflict often resulting. In turn, resulting changes in family behavior often occurred in modified or hybrid forms, rather than wholesale adoption of attributes labeled as modern.

\section{Conceptual Background}

The origins of developmental idealism culture lie in ideas of development and modernity formulated by scholars and elites in Northwest Europe and its diaspora from the late 1600s to early 1800 s, a period frequently referred to as the Enlightenment (Thornton 2001, Thornton 2005, Thornton, Dorius and Swindle 2015). These scholars believed societies move along a developmental trajectory from traditional and less developed to modern and more developed. As Northwest European elites, they ethnocentrically viewed their own societies as the pinnacle of that trajectory and categorized their own customs as modern. They thought societies outside Northwest Europe occupied earlier stages in the development trajectory and classified nonWestern practices as traditional and inferior.

Family life was part of this development trajectory. Enlightenment scholars believed family attributes of Northwest Europe were modern and the result of past progress, or development, from traditional family traits. Family practices of Northwest Europe they identified as modern included nuclear households, low fertility, individual autonomy, monogamy, 
marriages arranged by couples themselves at relatively mature ages, and considerable numbers never marrying. These scholars classified family behaviors practiced outside Northwest Europe as traditional and believed non-Western societies represented what family life was like in earlier stages of societal development. In turn, they classified extended family households, polygamy by some, nearly universal marriage arranged at young ages by parents, high fertility, extensive parental authority, and other customary non-Western family attributes as traditional (Thornton 2005: Chapter 3). They also evaluated women's status as higher in Northwest Europe than elsewhere, although research in recent decades seriously challenges this judgement (Thornton 2005:55-58, 90-91).

Scholars and other elites during the Enlightenment also formulated a belief system emphasizing the importance of freedom, equality, and consent in relationships that are core values within developmental idealism culture (Thornton 2005: Chapters 8-9). While individual consent had long been the basis of Northwest European marriage practices, the new emphasis on freedom and equality likely grew out of extensive cross-cultural interactions from the $1400 \mathrm{~s}$ onward. European exploration and colonization brought an amazing amount of new information and perspectives from numerous non-Western societies into Europe (Graeber and Wengrow 2021: 28-37, Lehmann 1979: 118-19, Thornton 2005: Chapters 2 and 8-9). Contact with people in North America may have been particularly influential in inspiring the emphasis on freedom and equality. One observation made by both Europeans and Indigenous people of North America was that Europeans had substantially less freedom and equality than did many Indigenous North Americans (Graeber and Wengrow 2021: Chapter 2; Thornton 2005:36-38). This contrast was so striking it led to a strong North American Indigenous critique of the extensive and longstanding structures of inequality and social control in European societies. This indigenous critique of European societies was widely disseminated in Europe and had such a powerful influence on the 
Enlightenment that "anyone objecting to existing intellectual and social arrangements would tend to deploy it as a weapon of choice: a game..... played by pretty much every one of the great Enlightenment philosophers" (Graeber and Wengrow 2021:61-62). With the Enlightenment, the values of freedom and equality became accepted lodestars of both individual and societal-level action among Northwest Europeans, guiding many social, political, economic, and individual decisions (Thornton, Dorius and Swindle 2015).

The relevance of developmental idealism to family life in contexts outside Northwestern Europe and its diaspora is readily apparent. Family change in non-Western contexts, such as fertility decline and later, self-choice marriages supplanting early and arranged marriage, readily map onto the shift from traditional to modern family attributes predicted by developmental idealism theory. Most past research on developmental idealism also documents the adoption and influence of developmental idealism culture in non-Western contexts, including Nepal (Allendorf 2017, Thornton, Ghimire and Mitchell 2012), India (Allendorf 2013, Allendorf and Pandian 2016), China (Lai and Thornton 2015, Yu and Xie 2015), Iran (Abbasi-Shavazi, AskariNodoushan and Thornton 2012, Loeffler and Friedl 2014), Kenya (Watkins and Hodgson 2019), Malawi (Thornton et al. 2014), and Turkey (Kavas and Thornton 2013, Kavas and Thornton 2020).

Developmental idealism theory may appear less relevant to Northwest Europe and its diaspora populations in the United States and elsewhere. Enlightenment scholars identified some family attributes as modern precisely because those behaviors were practiced in their own, Western societies. Thus, one may wonder how adoption of developmental idealism could spur the rise of behaviors labeled as modern in places where those behaviors were already practiced. The answer lies in a mix of internal variation within Western societies, the expansion of 
attributes labeled as modern, and the developmental idealist belief that even Western societies continue to develop. While Enlightenment scholars viewed their own societies as occupying the pinnacle of development, their progress was not seen as ending in 1800 or 1900 . Western societies too were seen as able to progress yet further or regress and decline. Crucially, Western societies were seen as further advancing while maintaining their pinnacle position - they were conceptualized as leaders of the development trajectory with non-Western societies following behind.

Internal variation within Western societies gave space for family attributes originally labeled as modern by early scholars to increase. Family attributes were originally identified as modern because they were practiced in Northwest Europe, but they were not universal, as Western societies, like all societies, had a mix of traditional and modern traits as defined by developmental idealism (Thornton 2005:150). For example, many families in Northwest Europe had nuclear households consisting of husbands, wives, and children, but there were also more extended stem households with grandparents living with parents and children. Similarly, while people typically married at comparatively mature ages in Northwest Europe, there was a range of marital ages from relatively young to old, and some never married at all. In addition, there were sizeable differences in numbers of children born in families due to differences in underlying fecundity, age at marriage, and economic resources. Thus, it was possible for many attributes identified as modern within developmental idealism, like nuclear families, older age at marriage, and low fertility, to increase further in Western societies (Thornton 2001, Thornton 2005:Chapters 8-10).

Developmental idealism also inspired further change by placing attributes along a traditional/modern continuum and valorizing changes in the modern direction as natural and 
good. Such directionality is clearest for quantitative attributes. For instance, age at marriage and fertility run along quantitative continuums of years of age and numbers of children born.

Developmental idealism classifies low age at marriage and high fertility as traditional, inferior, and harmful, while high age at marriage and low fertility are viewed as modern, superior, and helpful even within Western societies. In turn, this continuum logically implies people marrying later and later and having fewer and fewer children is progress. While women marrying in their early twenties was viewed as modern in 1800, pushing marriage to older ages in the late twenties or early thirties in the 1990s and 2000s is consistent with even greater modernity. Conversely, marrying earlier in their teens would have seemed like going backwards or regressing. Moving further away from attributes labeled as traditional provides direction for progress on nonquantitative attributes too. For instance, Enlightenment scholars defined nuclear family households as modern because they were common in Northwest Europe, but also because of the contrast with extended families of India and China, which they viewed as embodying the traditional. If progress is moving away from extended families, then it entails more nuclear families, but perhaps also family forms with even fewer family ties and members, such as living alone or in single parent households.

Family attributes labeled as modern also expanded through the extension of core values of freedom and equality to new behaviors. As noted above, developmental idealism culture presents freedom and quality as fundamental values and primes people to believe family change is a natural part of development with Western societies leading the way. In turn, family attributes that arise in Western societies after the Enlightenment - in the late 1800s, 1900s, and 2000s could be newly identified as part of the modern family as they came to be understood as consistent with freedom or equality and a next step in ongoing progress. For example, divorce was not originally part of the modern family identified by Enlightenment scholars, but later 
became seen by many as part of the modern family when it was framed as an extension of freedom in the late 1900s (Thornton 2005:167-72).

Western societies are uniquely positioned to expand attributes identified as modern because they were (and are) widely viewed as leading the development trajectory - first by Enlightenment scholars, but later by many ordinary people. Many people and institutions around the world, including the United Nations, World Bank, and other development organizations continue to use concepts of traditional and modern societies and perceive the United States and other Western countries as sitting atop a developmental hierarchy (Thornton et al. 2012a). In turn, family changes that occur in the United States and other Western societies are viewed by many as harbingers of changes that other societies will likely, if not inevitably, experience too as they develop further. Many people in non-Western countries associate family behaviors that arose only recently in the 1900s, like divorce, premarital sex, and nonmarital childbearing, with modernity (Abbasi-Shavazi, Askari-Nodoushan and Thornton 2012, Binstock and Thornton 2007, Kavas and Thornton Forthcoming, Thornton, Binstock and Ghimire 2008, Yount et al. 2017). Ordinary people around the world likely view such behaviors as modern because they are practiced more in the West and the West is seen as consistently leading the way for development. Large majorities of Americans also associate divorce, cohabitation, and premarital sex with developed societies (Richardson and Allendorf 2022). It is likely many Americans, as well as Western Europeans, also associate other more recent family behaviors with modernity and progress, although we are not aware of studies that examine such linkages.

The strong new emphasis on freedom and equality brought by the Enlightenment is another key to understanding how developmental idealism could have an influence in the United States and other Western countries. Freedom and equality are relatively general and abstract 
concepts, but over the centuries they have been applied vigorously in many concrete circumstances in Western countries, bringing great resistance and conflict, as well as enormous social change. Their most immediate application was in "the political arena, becoming a driving force in the creation of democratic political principles worldwide, and playing a prominent role in the French and American Revolutions" (Thornton 2005:145). At the founding of the United States, Thomas Jefferson wrote in the American Declaration of Independence that "We hold these truths to be self-evident, that all men are created equal, that they are endowed by their creator with certain unalienable rights, that among these are life, liberty and the pursuit of happiness" (https://www.archives.gov/founding-docs/declaration-transcript; capitalization standardized). Given the political structures of the time, this Declaration was met with considerable resistance and conflict, resulting in a long and bloody war, but an independent new country was established. And, although this declaration of equality and liberty was authored by a slave holder and endorsed by other slave holders, it took an abolition movement and a Civil War to end slavery nearly a century later, and it took a Civil Rights Movement a hundred years later, in the 1960s, to establish a framework of freedom and equality for the descendants of former slaves. And, in the 2020s, the struggle to realize racial equality is yet again at the forefront of American society.

The strength of the values of freedom and equality to motivate action and generate resistance and conflict is similarly powerful in the family arena. The proposition that "all men are created equal, that they are endowed by their creator with certain unalienable rights" was applied to women and sparked movements for gender equality, universal suffrage, the unsuccessful effort to pass an equal rights amendment, and numerous court cases to establish gender equality. The idea that people should have the freedom to control their fertility led to intensely contested efforts to legalize contraception and abortion and make them widely 
available. The freedom to end an unhappy marriage was advocated, and despite resistance, eventually culminated in an era of relatively free divorce. More recent is the social movement to provide freedom and equal rights to gays and lesbians, including the right to same-sex marriage. We also emphasize that while developmental idealism helps produce changes in family belief and behavior, we do not suggest changes in American family beliefs or behavior are inevitable or fully determined by developmental idealism. The forces opposing such transformations can be strong enough to prevent such trends, to make them happen slowly, level off, or even reverse.

\section{Hypotheses}

We expect support of developmental idealism culture expanded in the United States during the last half century. This hypothesized expansion includes increasing endorsement for attributes with longer histories of being classified as part of the modern family of developmental idealism, including gender equality, low fertility, never marrying, and delayed marriage and childbearing. We also hypothesize this expansion was reflected in increased support for attributes, which for many, became part of the modern family of developmental idealism only later in the 1900s and early 2000s, including divorce, premarital sex, nonmarital cohabitation, nonmarital childbearing, extramarital sex, and same-sex relations.

There are important aspects of the developmental idealism perspective that we do not examine. We are not able to identify the consequences of developmental idealism for family behavior in the United States. Identifying characteristics associated with higher or lower acceptance of developmental idealism, such as education, race/ethnicity, income, region, religiosity, age, marital status, number of children, geographical residence, and migration, is also outside the scope of this paper. Richardson and Allendorf (2022) find consistent differences in Americans' endorsement of developmental idealism about marriage and unions by education and 
race. Other studies extensively address variation in developmental idealism in many places outside the West, including Iran (Abbasi-Shavazi, Askari-Nodoushan and Thornton 2012), Turkey (Kavas and Thornton 2013, Kavas and Thornton 2020), China (Lai and Thornton 2015, Thornton and Xie 2016), Argentina (Binstock and Thornton 2007), Egypt (Yount et al. 2017), Nepal (Thornton, Ghimire and Mitchell 2012, Thornton, Young-DeMarco and Ghimire 2012), Malawi (Thornton et al. 2014), and Albania (Gjonça and Thornton 2019). Similarly, there are useful discussions of the consequences of development idealism in relation to several countries, including Nepal (Allendorf 2017, Allendorf et al. 2019, Thornton, Binstock and Ghimire 2008), India (Allendorf 2013, Allendorf and Pandian 2016), Iran (Loeffler and Friedl 2014, Yount and Rashad 2008), Central and Eastern Europe (Thornton and Philipov 2009), Kenya (Watkins and Hodgson 2019), Turkey (Kavas and Thornton Forthcoming), Tunisia (Yount and Rashad 2008), Egypt (Yount and Rashad 2008), and Indonesia (Cammack and Heaton 2011).

Before turning to our data, we emphasize that we are neither endorsing, nor critiquing developmental idealism culture. We take no position concerning whether the attitudes and behaviors of developmental idealism are actually good or bad, nor the beliefs true or false. Our goal is limited to assessing whether trends in family attitudes and beliefs are consistent with the expansion of developmental idealism culture in the American population during the last half century. We only use the language of development and modernity to describe the beliefs and attitudes of developmental idealism; this developmental language does not portray our own views of societies, individuals, and family traits. 


\section{Data and Methods}

Data

We use data from four large-scale, longitudinal surveys. Three of these surveys are trend studies, which collected family attitudes from cross-sections of Americans from the 1970s or 1980s through the 2010s. These three surveys comprise the General Social Survey (GSS), the American component of the International Social Science Project (ISSP), and Monitoring the Future (MTF). The fourth data source is a panel study that ended earlier in 1993, the Intergenerational Panel Study of Parents and Children (IPSPC). We include the IPSPC because it began in the early 1960s, allowing us to examine earlier trends and highlight a decade in which pronounced attitudinal shifts occurred. We describe each data source and then turn to our analysis.

General Social Survey (GSS). The GSS is a long-running social indicator data collection project conducted by the National Opinion Research Center at the University of Chicago (NORC). Surveys on a wide variety of topics were administered yearly from 1972 to 1994, and then biannually from 1996 onwards. Each survey is an independently drawn sample representing the English-speaking adult population (aged 18 years and above) not living in institutional quarters. In turn, a limitation is large numbers of young adults living in college dormitories and other institutions were excluded. We therefore restrict our GSS analytical sample to persons ages 24 and older. We include GSS waves covering 1974 through 2018. Adjacent years of data are averaged where possible for years prior to 1996, followed by averaged pairs of adjacent data collections occurring in 1996/1998, 2004/2006, and 2014/2016. We also include 2018 by itself because it is the last year of data collection before the response rate and mode changed substantially in 2020 due to the coronavirus pandemic. 
International Social Science Program (ISSP). The International Social Science Program (ISSP) was organized in the early 1980s to provide comparable attitudinal data in numerous countries. Each survey year features a topical module, which were repeated at regular intervals throughout the project's three decades. The United States data collection is conducted by NORC under the auspices of the GSS. A subsample of the GSS is administered the ISSP module in addition to the main GSS instrument. Questions fielded in the ISSP module are generally unique to the ISSP subsample, although occasionally some overlap occurred. When that happens, the ISSP sub-sample responds to the question located within the ISSP module, while all other respondents answer the question where it appears within the GSS survey. Since ISSP module data are stored in uniquely named variables not used by any of the corresponding GSS questions, it allows for separate analysis of matching questions in years with overlaps. As it happens, three of the variables we analyzed were asked in both surveys, but none of the years we represent in our analyses of the GSS and the ISSP overlap. (See the Online Appendix for further details.) We include data from the "Family and Changing Gender Role" module fielded in 1988, 1994, 2002, and 2012, and - as we did with the GSS - limit the analytical sample to adults aged 24 and older.

Monitoring the Future (MTF). In 1976, investigators at the Survey Research Center of the University of Michigan began collecting nationally representative data from students in about 410 public and private high schools throughout the coterminous United States. Our MTF analytical sample comprises high school seniors - the target of the original sampling and source of the most comprehensive coverage of family attitudes. Data were collected via selfadministered questionnaires completed during school hours under the guidance of University of Michigan staff (Miech et al. 2020). Each decade is represented by the following averaged paired years of data: 1976-1977, 1986-1987, 1996-1997, 2006-2007, and 2016-2017. 
Intergenerational Panel Study of Parents and Children (IPSPC). Between 1962 and 1993, data were collected intermittently from a probability sample of Detroit Metropolitan area white women who gave birth in 1961 (Thornton, Freedman and Axinn 2002). Birth records provided the sample universe, and approximately equal numbers of women who had borne their first, second, or fourth child were selected using systematic random sampling. During the first two waves (1962 and 1977), only mothers were interviewed, while the children born in 1961 became respondents too in three later waves (1980, 1985, and 1993) of intergenerational panel data. Our IPSPC analytical sample comprises the mothers who appeared in all five waves, comprising $80 \%$ of mothers originally interviewed in 1962 .

\section{Measures and Analysis}

Our measures include over 60 items assessing a range of attitudes and beliefs about family life. We required item wording to remain identical across waves within a data source, but not across sources. Most items appeared in the earlier studies on family attitudes (Thornton 1989, Thornton and Young-DeMarco 2001). We also added new items on ideal numbers of children and same-sex relations. We provide exact wordings of each item in the Online Appendix.

We present trends in these family attitudes and beliefs by sex. For each measure and survey wave, we present weighted percentages of women and men holding a particular attitude or belief, generally the percentage agreeing or disagreeing to a family-related statement. We also tested if differences between adjacent survey waves were statistically significant. Except for the IPSPC study that used a straightforward systematic sampling procedure, variance estimates between decades were produced assuming a complex sample design, rather than simple random sampling to avoid underestimation of variances. 
To ease comparisons, we generally present percentages of women and men holding attitudes consistent with developmental idealism. Thus, we largely expect percentages of men and women holding these attitudes to rise over time. However, some measures are coded in the opposite way, such that a decrease over time is indicative of growing developmental idealism. Coding for each item is in the Online Appendix.

Results for all 60 items are shown in the Online Appendix. These tables include point estimates, as well as sample sizes and statistical significance of differences between adjacent waves. As noted above, starting and ending points of data collections vary across our four data sources; they also vary for individual items within sources due to surveys adding new items and discontinuing old ones across waves.

We focus our descriptions of results from the GSS, ISSP, and MTF data sets on measures collected through the 2000s or 2010s, extending beyond the earlier assessment using these sources which ended in the late 1990s (Thornton and Young-DeMarco 2001). However, trends for these GSS, ISSP, and MTF measures only date back to the 1970s. To cover earlier periods, we supplemented items from these studies with a handful of IPSPC items dating back to 1962. In total, we present trends for just over 30 attitudes and belief items from the four sets of surveys in graphs in which trends for women are depicted as solid lines and men's trends as dashed lines.

There are noteworthy particularities and limitations of our analyses. First, inconsistencies in trends across data sources are likely due to differences in measures and item wording, as well as target populations. We therefore focus on changes over time within data sources, rather than between them. Five items also present challenges to perfect comparability within a source. Starting in 1997, MTF stopped administering five family-related items in California due to state requirements. Using earlier waves, we found results are nearly identical with and without the 
Western region. Thus, we retained these items despite the change in geographic coverage. We give further details in the Online Appendix.

Our trend evidence is also left-censored. What we present for this half century may represent a variety of longer attitudinal trend types; including continuing of trends dating back to even earlier period, the emergence of completely new trends, and trends that fluctuated over time. Family attitude studies dating to earlier decades are few, but suggest developmental idealism was expanding prior to the 1960s (Alwin 1988, Reiss 1967, Veroff, Couvan and Kulka 1981).

Finally, differences in analytical samples have important implications for interpreting processes of change over time. As noted above, the GSS and ISSP provide estimates of attitudes across a wide range of adults (aged 24 and above), while MTF represents young people just entering adulthood (high school seniors). Thus, changes over time observed in GSS and ISSP may be due to both period and cohort effects; that is, genuine changes in the same people's attitudes across time, as well as older cohorts exiting the population through mortality as younger cohorts are aging into it. In the case of MTF, period and cohort effects are confounded due to the narrow focus on high school seniors. As a panel of mothers followed over a thirty-year period, the IPSPC allows us to assess changes in attitudes within an identical group of individuals. Thus, unlike the other data sources, trends from IPSPC confound age and period effects.

It is also important to note that the United States population has not been a static one during the fifty years of this study. Instead, the population has been dynamic, changing on many dimensions because of differential fertility and mortality by such dimensions as race, ethnicity, and religion. There have also been changes in education, income, age, and other socioeconomic and demographic attributes. While we emphasize the importance of such factors, examination of 
them is outside the scope of our paper. In addition, there have been important migration streams during this half century, both domestic and international. While we simplistically characterize the United States as part of the Northwest European diaspora, a growing share of the population is composed of migrants and their descendants from places outside Northwest Europe, as well as Native Americans.

\section{Results}

We begin our discussion of results with trends in attitudes and beliefs towards family attributes formulated as modern by the scholars of the Enlightenment from the late 1600s through the 1800s and incorporated as such in developmental idealism culture, including gender relations, marriage, and childbearing. Next, we turn to trends in attitudes and beliefs about family attributes that emerged as modern later through extensions of traditional/modern continuums or applications of developmental idealism's emphasis on freedom and equality. Attributes that entered the modern family of developmental idealism in the 1900s or even 2000s, include divorce, heterosexual premarital and extramarital sex, cohabitation, nonmarital childbearing, and same-sex relations.

\section{Gender relations}

We divide our description of trends in gender attitudes along three substantive dimensions - decision-making, division of labor, and child rearing. Each of our four data sources asked respondents whether they agreed or disagreed with statements mapping onto these three dimensions of the family. Attitudes shown in Figures 1 and 2 are all coded such that increases denote greater egalitarianism and consequently expansion of developmental idealism.

We begin with decision-making, specifically the extent to which Americans believed women and men should have equal authority. Egalitarian views of decision-making in line with 
developmental idealism increased sharply at the beginning of the half century, but then flattened with hints of waning (Figure 1, top). In 1962, a third of mothers interviewed in the IPSPC took an egalitarian view of decision-making, disagreeing that "men should make important family decisions." When these same mothers were interviewed 15 years later, in 1977, this share doubled to $67.0 \%$. More of these mothers acquired egalitarian views from 1977 to 1993 , as this percentage rose steadily higher to $83.9 \%$.

Later views of IPSPC mothers were remarkably similar to those of young women, but not men, during the same period. In 1976-77, 71.9\% of women high school seniors interviewed in MTF took a developmental idealism view, disagreeing a "husband should make important family decisions." This percentage rose to $86.6 \%$ in $1996-97$ and then sank to just under $80 \%$ through the 2000s and 2010s. Young men's views were consistently and substantially less egalitarian, but changes over time were similar. In 1976-77, only $44.1 \%$ of male high school seniors disagreed that the "husband should make important family decisions." This point estimate rose slightly to a high of $49.6 \%$ in the $1990 \mathrm{~s}$. It reversed course in the $2000 \mathrm{~s}$, falling slightly, and then tilted upwards again in the $2010 \mathrm{~s}$, but these latter shifts were not statistically significant.

[Figure 1 about here]

Egalitarian attitudes about a gendered division of labor show steadier growth in line with developmental idealism, but with signs of temporary softening in the late 1990s and early 2000s (Figure 1, bottom). In 1962, nearly half of IPSPC mothers believed wives could expect husbands to help around the house and over half rejected a clear division of men and women's work. Apart from an outlier wave in 1977 on one item, these shares rose steadily to strong majorities of over and just under $80 \%$ respectively in 1993 . From the 1970 s to the 1990 s, successive cohorts of high school seniors showed a similar trend of growing egalitarianism. Percentages rejecting a 
breadwinner/ homemaker family rose from $42.1 \%$ to $72.3 \%$ among women and from $17.3 \%$ to $39.0 \%$ among men. These shares taking an egalitarian view fell markedly by over 10 percentage points for men and women in the 2000s, but then regained ground by the 2010s. Unlike teenagers, adults' attitudes showed a steady trend towards egalitarianism from the 1970s through the 2010s. Percentages of adult women and men rejecting the breadwinner/homemaker family rose from a third in 1977 to strong majorities of $79.2 \%$ and $70.6 \%$ respectively in 2018 . The pace of growing egalitarianism among adult women softened from the mid-1990s to 2000s, but resumed and rose sharply in the 2010 s.

[Figure 2 about here]

From the 1970 s to 2010 s, there was also growing conviction that women working outside the home does not pose adverse consequences for child rearing (Figure 2). GSS, ISSP, and MTF all asked respondents whether "a working mother can establish just as warm and secure a relationship with her children as a mother who does not work" and if "a preschool child is likely to suffer if his or her mother works." Levels differed across sources, but all three sources document growing belief that women's work outside the home is not harmful. While these beliefs rose among women and men, the share of women holding them was consistently higher.

\section{Marriage}

As mentioned earlier, Northwestern European scholars of the Enlightenment period recognized marriage was valued in their region - but unlike in many other societies - was not universal and did not usually occur at young ages. Late and non-universal marriage became part of what these scholars described as modern marriage and was integrated into developmental idealism culture. To examine American trends in these aspects of developmental idealism, we are limited to survey questions that asked people to compare marriage with remaining single and 
asked teenagers to express their level of commitment to getting married sometime, as well as the ideal timing of marriage.

We start with adults' beliefs about marriage with the only marriage-related item administered to those aged 24 and older - an ISSP question asking if "married people are generally happier than unmarried people." Trends in this belief, suggest modest, but meaningful, changes in adults' views of marriage (Figure 3, top). In 1988, a mere 14.8\% of women and $11.4 \%$ of men disagreed with this statement - saying married people are not generally happier. Disagreement grew steadily over time reaching highs of a third of women and a fifth of men at the last wave in 2012. Thus, the share rejecting a marital advantage in happiness, doubled in roughly two and a half decades and reached sizable numbers, which points to a meaningful destabilization of marriage. However, this developmental idealist view was held by only a minority through the 2010 s, indicating continued commitment to marriage among most Americans.

[Figure 3 about here]

Our assessment of marriage-related trends among young people at the cusp of adulthood is more comprehensive since MTF included five items. These trends suggest continued commitment to marriage, but alongside meaningful changes, especially at the end of the period (Figure 3). We begin with an item similar to the ISSP measure administered to adults. MTF asked high school seniors if "most people will live fuller and happier lives if they choose legal marriage, rather than staying single or just living with someone." In 1976-77, 40.5\% of young women and $36.9 \%$ of young men disagreed, taking a developmental idealist stance. Among women, this belief held steady at just over $40 \%$, but with a temporary dip in the 2000 s. Young 
men's disagreement eroded steadily from the 1970 s high to a low of $24.2 \%$ in the $2000 \mathrm{~s}$, and then rebounded slightly, but not significantly, to $28.3 \%$ in the $2010 \mathrm{~s}$.

The other MTF item measuring beliefs about marriage shows a similar trend, with sizable minorities of young adults questioning married life. From the 1970 s through the 2010 s, roughly a third of young women and men agreed "one sees so few good or happy marriages that one questions it as a way of life." The overall trend is stable, but a finer-grained assessment points to slight, but potentially meaningful changes, including a swelling of discontent in the 1980s, erosion in the $1990 \mathrm{~s}$, plateauing in the $2000 \mathrm{~s}$, and then a resurgence of discontent in the $2010 \mathrm{~s}$.

When young adults were asked about their own futures, however, a widespread and broadly stable commitment to marriage emerges (Figure 3, bottom). Throughout the period, large majorities, $70-80 \%$, believed they would marry and identified a good marriage and family life as extremely important in their own lives. A finer-grained assessment again points to small, but potentially meaningful, shifts over time. In 1976-77, nearly identical shares of young women, $79.0 \%$ and $78.5 \%$ respectively, identified a good marriage and family life as extremely important in their own lives and believed they would eventually marry. These percentages rose slightly in the 1980s, held steady through the 1990s and 2000s, but then eroded in the late 2010s. In 197677, young men began with somewhat lower commitment to marriage, about $70.9 \%$ believed they would marry and $67.1 \%$ viewed marriage as extremely important. Similar to young women’s shifts, this commitment to marriage in young men's own lives swelled by 5-10 percentages points for the next few decades, but then eroded in the 2000s, ending back at 1970s levels around $70 \%$ in $2016-17$.

Young adults also remained committed to marrying at some point, but more and more believed that point should come later in life. There was a striking increase in the share of high 
school seniors who believed the ideal time to marry is over five years away, corresponding to their mid-twenties or later (Figure 3, bottom). In 1976-77, only a minority expected to marry late, with $20.7 \%$ of young women and $36.0 \%$ of young men saying the ideal time was over five years away. Over the next two decades, these percentages roughly doubled to $43.5 \%$ and $53.7 \%$ among young women and men respectively. From the 1990s to 2000s, expectations of late marriage plateaued - point estimates declined slightly, but these apparent declines were not statistically significant. At the end of the period, however, there was a resurgence of this developmental idealist view; endorsement of late marriage spread even further, reaching majorities of $53.9 \%$ of young women and $62.8 \%$ of young men, in 2016-17.

\section{Childbearing and Fertility}

Next, we turn to childbearing, describing trends in attitudes towards parenthood and ideal numbers of children. At the beginning of the half century, there was a dramatic increase in viewing marital childbearing as optional, rather than compulsory (Figure 4, top). In 1962, only $7.1 \%$ of IPSPC mothers rejected the view that "almost all married couples who can ought to have children.” By 1980, nearly two decades later, this optional view was held by $54.0 \%$ of the mothers, rising from a trivial fraction to the majority. This developmental idealist view then held steady, at just over half, through 1993 when data collection ended.

[Figure 4 about here]

In the middle of the half century, ISSP began measuring adults' views of children's impact on parents' lives. They asked if "children interfere too much with parents' freedom" and if "people who never had children lead empty lives." Trends in these items further suggest many continued to value parenthood, but increasingly viewed it as optional (Figure 4, top). In 1988, just under half of women and men believed childless people do not lead empty lives. This share 
rose to over half of women in the 1990s and to nearly two-thirds in the early 2000s, while it held steady for men. This trend indicates growing numbers viewed childlessness as acceptable, if not desirable. Yet, a large majority also valued parenthood positively. In 1988, even larger numbers, $76.8 \%$ of both women and men, rejected the view that children interfere too much with parents' freedom. Among women, this view rose slightly in the 1990s and then fell in the 2000s, but was still held by a large majority. Among men it fell slightly and then held steady at just over 70\%. Together, these seemingly contradictory trends suggest large numbers of adults viewed both parenthood and childlessness as acceptable, which is consistent with childbearing increasingly being a matter of individual choice.

Trends for high school seniors also show continued commitment to parenthood, but with a swelling at the beginning and slackening at the end (Figure 4, bottom). In 1976-77, two-thirds of young women believed "being a mother [or father] and raising children is one of the most fulfilling experiences a woman [or man] can have." A majority also expected to become mothers with 59.3\% "very likely" wanting children in the future. These percentages rose modestly, but significantly, by 4-10 percentage points, into the 1980 s and 1990 s, reaching a gentle plateau in the 1990s and 2000s. In the late 2010s though, there was a marked drop of roughly the same size. Trends in young men's views of fatherhood and expectations of wanting children show similar trends - rising gently from sizeable majorities, plateauing, and then falling. Young men's attitudes towards motherhood, in particular, also pose a partial exception. Positive views of motherhood were less widespread among young men, with just under half viewing it as fulfilling in the 1970s. Further, rather than positive attitudes swelling into the 1980s and 1990s, young men's views of motherhood soured in these decades. Motherhood regained ground in young men's estimation in the 2000s, but then, like the other childbearing attitudes, slackened into the 2010s. Although majorities of young men and women still expected to become parents at the end 
of the period, these majorities were slim. In $2016-17,57.2 \%$ of young women and $53.8 \%$ of young men believed it "very likely" they would want children.

Adults' attitudes towards numbers of children were collected by the GSS and ISSP from the 1970s onwards. We show estimates from these sources as a single set of trends in percentages viewing exact numbers of children as ideal, as well as the overall mean in ideal numbers in Figure 5. Excluded from the calculations are 4-12\% of GSS respondents across the years who answered "as many as you want" since it was not possible to include answers of this type in the mean and this answer category was not offered in the ISSP. We show one set of trends using these two sources because the analytical samples and item wordings were nearly identical, and results do not differ appreciably.

Overall, the mean number of children considered ideal dropped markedly in the 1970s, held stable at about two and a half children for several decades, and then rose slightly in the last decade (Figure 5). At the earliest wave, in 1972, the average ideal number of children was three, which is consistent with intermediate fertility levels. An ideal of two children comprised the mode, with $39.0 \%$ of women and $45.6 \%$ of men identifying two as ideal, but this two-child ideal did not (yet) garner a majority. The overall mean was higher, at three children, because sizable shares identified larger numbers as ideal. Notably, about a quarter of women and men preferred three children, $21.6 \%$ of women and $18.8 \%$ of men preferred four, and over $10 \%$ of women and just under $10 \%$ of men preferred five or more.

[Figure 5 about here]

Just a few years later, in 1976-77, the mean ideal number of children dropped by nearly half a child to 2.6 (Figure 5). This early drop was driven by increases in the two-child ideal and corresponding declines in ideals of three or more children. The most striking change was the 
increase in a two-child ideal, which rose from the strong plurality of 1972 to (slim) majorities of $53.6 \%$ of women and $51.0 \%$ of men in 1976-77. Shares choosing one child, or even zero, as ideal also rose, but remained negligible at $3.7 \%$ and $4.8 \%$ of women and men respectively. Absolute declines in percentages of women and men identifying larger numbers of children as ideal were evenly distributed, with shares identifying each of these numbers as ideal dropping by roughly four percentage points each. In relative terms, declines in identifying five or more children as ideal were substantial, roughly halving in size and falling below 5\%.

Trends in mean ideal numbers were steadily consistent with the desirability of low, but not too low, fertility at roughly two and a half children from the late 1970s onwards (Figure 5). This stable mean was supported by majorities of women and men who said two children were ideal from the late 1970s through the 2010s. Shares who viewed less than two children as ideal remained trivial. The share who said one child was ideal held at a tiny fraction of $1-3 \%$, while the percentage endorsing zero was roughly half that size. These percentages were so low, we combined zero and one children into a single category to make it visible in the graph. Similarly, the share who said large numbers of children - five, six, or seven - were ideal, held consistently at around $1 \%$ each and $3 \%$ collectively.

Although trends in ideal numbers were broadly stable from the late 1970s onwards, there was a modest $u$-shaped trend in the mean. Ideal numbers eroded towards the two-child ideal, until reaching a mid-1990s nadir, and then swelled back up through the end of the 2010s (Figure 5). The mean ideal eroded slightly from 2.6 in the late 1970 s to 2.4 in 1997. This erosion was driven by a rise in the two-child ideal from the slim majority of just over half in the late 1970s to nearly two-thirds of women and men in the 1990s. Correspondingly, percentages in favor of four 
children fell gently to roughly half 1970s levels by the 1990s. Percentages favoring three children, as well as extremes of less than two and five or more, held steady at trivial numbers.

The tilt towards higher fertility at the end of the half century is just visible in the overall mean. From the 1990s low of 2.4 children, the average ideal swelled to 2.6 children in the late 2010s. Underlying this slight change in the mean, were marked changes in percentages favoring two and three children. The two-child ideal fell in favor from its 1990 s high of over $60 \%$, returning to slim majority status by the end of the 2010s. In its place, the three-child ideal gained ground. Shares favoring three children rose from $20.2 \%$ of women and $24.4 \%$ of men in $1996 / 98$ to $31.1 \%$ and $28.2 \%$ respectively in 2018 . There is even a hint this tilt towards valuing higher fertility may be gaining further ground among women; percentages of women saying four children was ideal rose from $9.6 \%$ in 2012 to $12.1 \%$ in 2018 , while men held steady.

Next, we turn to family behaviors that entered the modern family of developmental idealism culture from the 1900 s. We order our discussion roughly by the times these attributes were incorporated, beginning with divorce and ending with same-sex relationships.

\section{Divorce}

At the beginning of the half century, a dramatic upswing in the acceptability of divorce occurred. In 1962, half of IPSPC mothers supported divorce $-51.1 \%$ believed parents of children should not stay together if they “don't get along” (Figure 6). By the next wave, in 1976, this developmental idealist view jumped to a large majority of $80.4 \%$. Acceptance of divorce then leveled off, rising incrementally to $82.7 \%$ among this cohort of mothers in 1993.

[Figure 6 about here] 
Young adults' expectations of whether they themselves might divorce in the future were collected by MTF. Overall, high school seniors' expectations were stable, with most anticipating intact marriages throughout the period. A finer-grained assessment points to swelling developmental idealism as this percentage eroded over time though, at least among women. In the mid-1970s, two-thirds of young women said they "very likely" would stay married if they married in future. This share slowly, but steadily decreased to $61.0 \%$ in $2016-17$. Young men were less sanguine about intact marriages and had a less consistent trend. In 1976-77, 56.7\% of young men believed staying married was very likely, this percentage dipped to $53.3 \%$ in $1986-$ 87, revived to $57.3 \%$ in $1996-97$, and then eroded back down to $53.8 \%$ in $2016-17$.

Trends in older adults' attitudes towards divorce were gently u-shaped from the 1990s to the 2010s, indicating acceptance of divorce fell and then rose. In 1994, just under half $-46.6 \%$ of women and $49.0 \%$ of men - agreed "divorce is usually the best solution when a couple can't seem to work out their marriage problems." These shares fell by a few percentage points to $37.9 \%$ of women and $43.4 \%$ of men in 2002, indicating Americans were becoming less tolerant of divorce. But, a decade later, this percentages rose back up to highs of $49.0 \%$ of women and $53.4 \%$ of men in 2012. At the end of the half century, acceptance of divorce reached a nominal high, but at around half of adults, support remained far from universal.

\section{Premarital and Extramarital Sex}

Next, we turn to heterosexual sex outside marriage and exclusive relationships, including premarital and extramarital sex. From the 1970s onwards, tolerance of premarital sex increased, but with a temporary stall in the late 1990 s and early 2000s (Figure 7, top). In 1974-75, 45.2\% of women and $53.6 \%$ of men said sex between a man and a woman before marriage was "not wrong at all" or "wrong only sometimes." These sizable percentages rose markedly by about 10 
percentage over the next decade. Acceptance continued to rise in the third decade, but at a slower pace, reaching $57.8 \%$ of women and $68.1 \%$ of men in $1996 / 98$. This rising trend then stalled, plateauing into the 2000s. In the last decade, the rising trend resumed, as acceptance increased again by over 10 percentage points. At the end of the half century, in 2018, a large majority of adults $-73.2 \%$ of women and $77.2 \%$ of men - tolerated, or even supported, premarital sex.

Acceptance of premarital sex between young teenagers was substantially lower, but also increased markedly at the end of the half century (Figure 7, top). In 1986, after asking the initial question about premarital sex between a man and woman of unidentified ages, the GSS began asking, "What if they are in their early teens, say 14 to 16 years old?" In 1986-87, small minorities were tolerant of premarital sex between young teenagers; $9.0 \%$ of women and $15.8 \%$ of men said it was not at all, or only sometimes, wrong. And, matching the stalling of attitudes on premarital sex more generally, trend lines were flat for the next two decades. In the 2010s though, acceptance of premarital sex among teens doubled, reaching highs of $21.9 \%$ of women and $27.6 \%$ of men in 2018 .

[Figure 7 about here]

Before turning to trends for extramarital sex, we note the measures depicted in Figure 7 are coded in opposite directions for premarital and extramarital sex. For premarital sex, percentages indicate belief that premarital sex is not wrong and increases in this support over time are consistent with expansion of developmental idealism. Conversely, the extramarital sex items indicate percentages who believe extramarital sex is wrong. With this reverse coding, our hypothesis of increasing endorsement of developmental idealism translates into declining trends in this opposition towards extramarital sex. 
Adults' views of extramarital sex were gently u-shaped - opposition to sex outside marriage rose slowly into the early 2000s and then declined back down to 1970s levels (Figure 7 , bottom). In $1975-77,76.1 \%$ of women and $68.1 \%$ of men said, "a married person having sexual relations with someone other than their marriage partner," was "always wrong" or "almost always wrong." These high levels of opposition increased over the next three decades, peaking at $84.3 \%$ of women and $77.4 \%$ of men in $2006-07$. The trend then reversed in the $2010 \mathrm{~s}$ as opposition eroded. By 2018, opposition returned to 1970 s lows with $77.5 \%$ of women and $71.9 \%$ of men viewing extramarital sex as wrong.

Trends in high school seniors' attitudes towards exclusive relationships showed a similar, gently u-shaped pattern of rising and then stabilizing, or even eroding, opposition (Figure 7, bottom). In $1976-77,65.5 \%$ of young women and $53.2 \%$ of young men disagreed that "having a close intimate relationship with only one person is too restrictive for the average person." This opposition swelled in the next two decades, peaking in 1996-97 at $75.1 \%$ of young women and $62.5 \%$ of young men. At the end of the period, trends diverged for men and women. Opposition stabilized among men through the 2010 s, holding steady at $62 \%$. Opposition declined slightly among women, falling by six percentage points to $69.3 \%$ in 2018 .

\section{Cohabitation and Nonmarital Childbearing and Childrearing}

Supportive attitudes towards nonmarital cohabitation rose over time, albeit with a temporary plateauing. The earliest measure dates to the 1970s, when MTF asked high school seniors about cohabitation as a precursor to marriage. In that early decade, a third of young women and nearly half of young men believed "it is usually a good idea for a couple to live

together before getting married in order to find out whether they really get along" (Figure 8, top). Support grew by roughly 20 percentage points through the mid-1990s, stalled through the mid- 
2000 s, and then rose again in the 2010s. By 2018, sizable majorities $-69.5 \%$ of young women and $73.4 \%$ of young men - supported cohabitation. A somewhat steeper increase among young women also narrowed the gender gap; support for cohabitation was 14 percentage points higher among young men at the beginning of the period, but only 4 points higher at the end.

[Figure 8 about here]

Adults' support, or at least tolerance, of cohabitation as an alternative to marriage also grew steadily (Figure 8, top). IPSPC and ISSP administered nearly identical items on cohabitation, asking if "it is alright for a couple to live together without intending [or planning] to get married." A developmental idealist view of cohabitation as "alright" grew from a quarter of IPSPC mothers in 1980 to a third in 1993. A year later, in 1994, a similar share of adult women interviewed in ISSP supported cohabitation, with $36.1 \%$ agreeing it was alright. Their support increased steadily, reaching half of women in 2012. Trends in men's support of cohabitation increased at a similar pace, but at a consistently higher level - rising from $43.3 \%$ in 1992 to $57.6 \%$ in 2012.

Support, or tolerance, of nonmarital childbearing also rose over time, but at a lower level and slower pace than for cohabitation (Figure 8, bottom). In 1988, when these attitudes were first measured, just over a tenth of adults supported nonmarital childbearing $-14.0 \%$ of women and $11.6 \%$ of men disagreed that "people who want children ought to get married." Among women, this percentage in line with developmental idealism rose in 1994 and again in 2002, reaching $23.0 \%$, but then held steady in 2012. The trend for men was flat - men's support for nonmarital childbearing held steady at $12-15 \%$ from 1988 to 2012 , holding just under and then markedly lower than women's support. 
Acceptance of single parenthood increased slowly and steadily among women and men, but was consistently higher among women (Figure 8, bottom). In 1994, 41.6\% of women believed "one parent can bring up a child as well as two parents together." This belief spread to nearly half of women in 2002 and rose further to a slim majority of 56.8\% in 2012. Men's endorsement of this developmental idealist belief swelled from just under a quarter in 1994 to a third in 2012. Notably, women's belief in the effectiveness of single parenthood was roughly 20 percentage points higher than men's across the period.

\section{Same-Sex Relationships}

Consistent with the extension of developmental idealism's principles of freedom and equality, support for same-sex relationships grew at an astonishingly rapid pace from the $1980 \mathrm{~s}$ onwards (Figure 9). The share of women and men believing "sexual relations with same sex partners" are "not wrong at all" or wrong "only sometimes" held at a fifth in the 1970s and early $1980 \mathrm{~s}$, but then surged to $65.2 \%$ of women and $57.1 \%$ of men in 2018 . Even more dramatically, the fraction of American adults believing "homosexuals have the right to marry" rocketed from a tenth in 1988 to a sizable majority four decades later. Percentages supporting same-sex marriage jumped from $12.2 \%$ to $70.7 \%$ among women and from $9.3 \%$ to $62.1 \%$ among men. These trends in women's and men's attitudes were remarkably similar, but women were slightly more supportive from the late 1980s onwards.

[Figure 9 about here]

\section{Discussion and Conclusion}

Overall, these trends demonstrate the expansion of development idealism culture in the United States over the last half century. From the 1960s through the 2010s, Americans' attitudes and beliefs about family life changed remarkably and in a largely consistent direction. Acceptability, and even desirability, of family attributes defined by developmental idealism as 
modern increased among adult women and men, as well as among high school seniors at the edge of adulthood. Support for family attributes designated as modern by Northwest European scholars of the 1600s to 1800 s expanded, as did support for attributes that entered the modern family of developmental idealism only later in time.

As theorized, internal variation was key to further support of the long-standing modern attributes of developmental idealism. Increases in support for family attributes designated as part of the modern family by Enlightenment scholars could increase in the last half century because approval was not universal at the beginning of our time span. In the 1960s and 1970s, there was sizable variation in Americans' attitudes and beliefs about gender relations, marriage, and fertility - all original aspects of the modern family of developmental idealism culture. With space to grow, endorsement of gender equality, late marriage, and low fertility could and did increase. Increasing gender egalitarianism was reflected from the 1960s in rejection of men's decision-making authority and gendered division of labor. A two-child ideal took hold of most Americans in the late 1970s, and young adults' expectations of marrying late - defined as their mid-twenties or older - spread to a majority only in the 2010 s.

Even at the end of the last half century, in 2018, quantitative continuums provided space for further growth in a modern direction of developmental idealism culture. As noted above, marital timing is anchored on years of age that can be pushed later and fertility on numbers of children that can be pushed even lower. With just over half of young adults expecting to marry in their mid-twenties or later, there is sizable room for further rises. For instance, in the 2010s, elite, single women living in New York City viewed their early thirties as the ideal time to marry (Fallon and Stockstill 2018). If such timing ideals became widespread in the US, it would push marital timing a decade later on a traditional/modern continuum of developmental idealism. In 
1800s Northwest Europe, the early twenties comprised late marital timing for women (Hajnal 1982). Fertility has less space to move since zero, or childlessness, provides a nearby floor on the continuum. However, Americans did not approach that floor - childlessness and even a one-child ideal were embraced by only trivial numbers across the last half century.

Expansion of developmental idealism culture is also seen in rising tolerance, and even desirability, of family attributes that were likely incorporated into the modern family of developmental idealism through extensions of freedom. Support grew for previously forbidden behaviors, including divorce, cohabitation, and same-sex relations, only in the mid to late 1900s. In the 1960s and 1970s, endorsement of married couples' freedom to divorce rose to a strong majority, while support for married couples' childbearing obligations evaporated. Similarly, support of individuals' rights to have sex and live with a partner outside of marriage not only rose across the half century, but garnered majorities by the end of the period. In the $2010 \mathrm{~s}$, most viewed cohabitation not only as a desirable precursor to marriage, but as an acceptable alternative. Acceptance of premarital sex also flourished, rising to three-quarters of Americans.

Other family attributes representing extensions of individual freedom were not endorsed by majorities, but did gain support. Non-marital childbearing and single parenting became increasingly acceptable, indicating growing numbers of Americans supported individual freedom even when parents' freedoms could affect their children (for better or worse). Notably, the belief that one parent is just as good as two spread to most women in the 2010 s, but not men. Growing numbers of Americans also accorded sexual freedom not only to adults, but to young teenagers. Tolerance towards premarital sex among teenagers aged 14 to 16 rose markedly in the 2010s, although a sizable majority still opposed it. Tolerance, if not support, for freedom to choose 
sexual partners outside marriage and exclusive relationships also grew modestly, although most Americans continued to believe extramarital sex is wrong.

Extensions of the developmental idealist value of equality is seen in the deepening embrace of equality between women and men. The value of equality has been affecting gender relations for centuries, but the less egalitarian breadwinner/homemaker model that emerged in the 1900s largely fell in favor of a more egalitarian, dual career family model from the 1970s through the 2010s. Americans increasingly rejected the notion that mothers' work outside the home would harm young children or damage the mother-child relationship. Equality also expanded to encompass sexual orientations for the first time. Support for same-sex relations and marriage soared in the last four decades as equal rights to sex and marriage were extended to same-sex partners (cf. Pan, Meng and Zhou 2010). Of course, this approval of same-sex marriage represented expansion of freedom too - individuals became free to marry the person they chose regardless of their sex.

Expansion of developmental idealism was not monotonic or constant across the half century though. Notably, several trends slowed or stalled in the late 1990 s and early 2000 s, including attitudes and beliefs about gender, marital timing, childbearing, cohabitation, and premarital sex. These stalls proved largely temporary though, as nearly all resumed in the late 2000 s or 2010 s. For instance, after stalling in the late 1990 s and 2000 s, gender egalitarianism rose even further with large majorities of adults and young women rejecting men's authority, a gendered division of labor, and adverse consequences of mothers working outside the home in the late 2010s. Young men pose a notable exception though. Substantial numbers of young men continued to embrace husband's authority and the male breadwinner/female homemaker model. Nonmarital childbearing comprises the other exception to temporary plateauing. Among women, 
support for nonmarital childbearing rose initially, but then remained stalled through the 2010s. And, among men, support was consistently flat.

While these trends illustrate profound changes in American attitudes, they also indicate continued commitment to family life, a commitment that seems to have remained in place for centuries. A few attitudes and beliefs showed little or even no change. Throughout the half century, sizable majorities of young adults expected to marry, stay married, and have children later in life. Many youth also continued to believe married life is generally good and married people happier and more fulfilled. Support for higher fertility even grew slightly in the last two decades; ideal numbers of children ticked upwards as a three-child ideal gained ground and the allure of childlessness and even one child remained negligible. Americans increasingly supported all individuals' freedom to choose from among a wide diversity of family behaviors, but most continued to favor marriage and children for their own lives.

Paradoxically, Americans continued commitment to marriage in some ways may contribute to its transformation in others. Commitment to marriage may have bolstered revolutionary changes in attitudes towards same-sex marriage. LGBTQ+ activists' argument that same-sex marriage is a natural extension of freedom and equality may have been effective in part because marriage is so highly valued. Depriving individuals of the right to marry a chosen partner may have been increasingly viewed as a travesty precisely because that right is considered so valuable in the United States. If cohabitation had been equally valued, the embrace of same-sex marriage may have been viewed as less important, even unnecessary.

A similar process may transform marriage further in the future, even relabeling one of the original traditional attributes in developmental idealism as modern. Activists may successfully argue the right to marry includes not only the freedom to choose a spouse's sex, but the number 
of spouses. As a form of marriage practiced largely in Africa and the Middle East, polygamy has long been considered traditional within developmental idealism culture. In keeping with that status, polygamy is illegal in the United States and widely viewed as unacceptable. There is also a domestic history of an internal American fight against polygamy that was characterized as a fight again a relic of barbarism (Gordon 2002). Yet, restricting marriage to two people could clearly be framed as a violation of individual freedom (Meek 2019). This potential transformation may comprise a refashioning of traditional polygamy into the modern "throuple" - a committed, sexually exclusive relationship of three people, linguistically represented by a mash-up of three and couple (Bote 2020, Karimi 2021). "Throuples" are gaining greater visibility and tolerance in American media, including positive portrayals on television (e.g. Paiella 2021). Attitudes towards "throuples," polygamy, and polyamory were not captured in our sources, but the uptick of tolerance towards extramarital sex and non-exclusive intimate relationships could be an early sign of a nascent trend.

Future research should address limitations of our analysis and push application of developmental idealism theory to Western societies further. Future studies should consider family and family-related matters included in the developmental idealism framework that we were unable to deal with in this paper. These include such issues of obedience and independence in childrearing, the extent to which families organize the daily activities of individuals, relationships of nuclear family members with the larger extended family, the matter of monogamy versus polygamy, and issues related to contraception and abortion.

Future studies should also examine how these ideational trends vary along important divides in American society, such as race/ethnicity, education, and birth cohort (Cherlin 2016, Crissey 2005, McLanahan 2004). It is also important to assess if Americans connect the 
preferred forms of family behaviors in developmental idealism to modernity and societal development. Developmental idealism theory contends a motivation for adopting family behaviors defined as modern within developmental idealism lies in people linking these behaviors to development. Our data sources did not contain measures about Americans' beliefs about the linkage of development to family attributes. Richardson and Allendorf (2022) did make a start by findings such linkages for some marriage behaviors. Future studies should also assess if these ideational trends contributed to changes in family behavior, further adding to the growing number of studies assessing if attitudes and beliefs influence individuals' behavior (e.g. Carlson, McLanahan and England 2004, Hurt 2013, Pessin 2018). Comparative historical case studies assessing if developmental idealism contributed to family changes in Western societies before the 1960s would also be valuable (cf. Thornton and Philipov 2009). 


\section{References}

Abbasi-Shavazi, Mohammad Jalal, Abbas Askari-Nodoushan and Arland Thornton. 2012.

"Family Life and Developmental Idealism in Yazd, Iran." Demographic Research 26:207-37.

Allendorf, Keera. 2013. "Schemas of Marital Change: From Arranged Marriages to Eloping for Love." Journal of Marriage and Family 75(2):453-69.

Allendorf, Keera and Arland Thornton. 2015. "Caste and Choice: The Influence of Developmental Idealism on Marriage Behavior." American Journal of Sociology 121(1):243-87.

Allendorf, Keera and Roshan K. Pandian. 2016. "The Decline of Arranged Marriage? Marital Change and Continuity in India." Population and Development Review 42(3):435-64.

Allendorf, Keera. 2017. "Conflict and Compatibility? Developmental Idealism and Gendered Differences in Marital Choice." Journal of Marriage and Family 79(2):337-55.

Allendorf, Keera, Arland Thornton, Colter Mitchell and Linda Young-DeMarco. 2019. "The Influence of Developmental Idealism on Marital Attitudes, Expectations, and Timing." Journal of Family Issues 40(17):2359-88.

Alwin, Duane F. 1988. "From Obedience to Autonomy: Changes in Traits Desired in Children, 1924-1978." Public Opinion Quarterly 52:33-52.

Andersen, Robert and Tina Fetner. 2008. "Cohort Differences in Tolerance of Homosexuality Attitudinal Change in Canada and the United States, 1981-2000." Public Opinion Quarterly 72(2):311-30.

Baunach, Dawn Michelle. 2011. "Decomposing Trends in Attitudes toward Gay Marriage, 19882006." Social Science Quarterly 92(2):346-63. 
Binstock, Georgina and Arland Thornton. 2007. "Knowledge and Use of Developmental Thinking About Societies and Families among Teenagers in Argentina." Demográfia English Edition 50(5):75-104.

Bote, Joshua. 2020, "What You Need to Know About Polyamory — Including Throuples — but Were Too Afraid to Ask" USA Today. Retrieved March 12, 2021, (https://www.usatoday.com/story/news/nation/2020/02/14/polyamory-everything-youneed-know-throuples-communication/4759860002/).

Cammack, Mark and Tim Heaton. 2011. "Explaining the Recent Upturn in Divorce in Indonesia: Developmental Idealism and the Effect of Political Change." Asian Journal of Social Science 39(6):776-96.

Carlson, Marcia, Sara McLanahan and Paula England. 2004. "Union Formation in Fragile Families." Demography 41(2):237-61.

Cherlin, Andrew J. 2012. "Goode's World Revolution and Family Patterns: A Reconsideration at Fifty Years." Population and Development Review 38(4):577-607.

Cherlin, Andrew J. 2016. "A Happy Ending to a Half-Century of Family Change?". Population and Development Review 42(1):121-29.

Coleman, James S. 1990. Foundations of Social Theory. Cambridge, MA: The Belknap Press of Harvard University Press.

Cotter, David, Joan M. Hermsen and Reeve Vanneman. 2011. "The End of the Gender Revolution? Gender Role Attitudes from 1977 to 2008." American Journal of Sociology 117(1):259-89.

Crissey, Sarah R. 2005. "Race/Ethnic Differences in the Marital Expectations of Adolescents: The Role of Romantic Relationships." Journal of Marriage and Family 67(3):697-709. 
Fallon, Katherine and Casey Stockstill. 2018. "The Condensed Courtship Clock: How Elite Women Manage Self-Development and Marriage Ideals." Socius 4:1-14.

Giddens, Anthony. 1991. Modernity and Self-Identity: Self and Society in the Late Modern Age. Stanford, CA: Stanford University Press.

Gjonça, Arjan and Arland Thornton. 2019. "The Spread of Ideas Related to the Developmental Idealism Model in Albania." Sociology of Development 5(3):265-85.

Goode, William J. 1963. World Revolution and Family Patterns. London: Free Press of Glencoe, Collier-MacMillan Ltd.

Gordon, Sarah Barringer. 2002. The Mormon Question: Polygamy and Constitutional Conflict in Nineteenth Century America. Chapel Hill, NC: University of North Carolina Press.

Graeber, David and David Wengrow. 2021. The Dawn of Everything: A New History of Humanity. New York, NY: Farrar, Straus and Giroux.

Hajnal, John. 1982. "Two Kinds of Preindustrial Household Formation Systems." Population and Development Review 8(3):449-94.

Hurt, Tera R. 2013. "Toward a Deeper Understanding of the Meaning of Marriage among Black Men." Journal of Family Issues 34(7):859-84.

Karimi, Faith. 2021, "Three Dads, a Baby and the Legal Battle to Get Their Names Added to a Birth Certificate": CNN. Retrieved March 12, 2021, (https://www.cnn.com/2021/03/06/us/throuple-three-dads-and-baby-trnd/index.html).

Kavas, Serap and Arland Thornton. 2013. "Adjustment and Hybridity in Turkish Family Change: Perspectives from Developmental Idealism." Journal of Family History 38(2):223-41.

Kavas, Serap and Arland Thornton. 2020. "Developmental Idealism and Beliefs About Marriage and Fertility in Turkey." Population Research and Policy Review 39(1):47-75. 
Kavas, Serap and Arland Thornton. Forthcoming. "Distinguishing between Old and New Developmental Idealism and among Beliefs About Correlation, Causation, and Expectations: Beliefs About Family Change and Development in Turkey." Sociology of Development.

Lai, Qing and Arland Thornton. 2015. "The Making of Family Values: Developmental Idealism in Gansu, China." Social Science Research 51:174-88.

Lehmann, David. 1979. Development Theory: Four Critical Studies. London: Routledge. Lesthaeghe, Ron J. 2010. "The Unfolding Story of the Second Demographic Transition." Population and Development Review 36(2):211-51.

Loeffler, A.G. and Erika Friedl. 2014. "The Birthrate Drop in Iran." HOMO-Journal of Comparative Human Biology 65(3):240-55.

Mason, Karen Oppenheim. 1997. "Explaining Fertility Transitions." Demography 34(4):443-54. McLanahan, Sara. 2004. "Diverging Destinies: How Children Are Faring under the Second Demographic Transition." Demography 41(4):607-27.

Meek, Philippa Juliet. 2019. "From Loving to Obergefell and Beyond: Plural Marriage as the Next Sexual Justic Issue." Intermountain West Journal of Religious Studies 10(1):6-27.

Miech, Richard A., Lloyd D. Johnston, Patrick M. O'Malley, Jerald G. Bachman, John E. Schulenerge and Megan E. Patrick. 2020. Monitoring the Future National Survey Results on Drug Use, 1975-2019: Volume I, Secondary School Students. Ann Arbor, MI: Institute for Social Research, The University of Michigan.

Paiella, Gabriella. 2021, "The Sweet Domestic Life of the House Hunters Throuple" GQ. Retrieved March 12, 2021, (https://www.gq.com/story/house-hunters-throuple-modernlovers). 
Pan, Po-Lin, Juan Meng and Shuhua Zhou. 2010. "Morality or Equality? Ideological Framing in News Coverage of Gay Marriage Legitimization." Social Science Journal 47(3):630-45.

Pepin, Joanna R. and David A. Cotter. 2018. "Separating Spheres? Diverging Trends in Youth's Gender Attitudes About Work and Family." Journal of Marriage and Family 80(1):7-24.

Pessin, Lea. 2018. "Changing Gender Norms and Marriage Dynamics in the United States." Journal of Marriage and Family 80(1):25-41.

Reiss, Ira. 1967. The Social Context of Premarital Sexual Permissiveness. New York: Holt, Rinehart, and Winston.

Richardson, Derek and Keera Allendorf. 2022. "Developmental Idealism and Beliefs About Marriage in the United States." SocArxiv.

Rosenfeld, Michael J. 2017. "Moving a Mountain: The Extraordinary Trajectory of Same-Sex Marriage Approval in the United States." Socius 3:1-22.

Shu, Xiaoling and Kelsey D. Meagher. 2018. "Beyond the Stalled Gender Revolution: Historical and Cohort Dynamics in Gender Attitudes from 1977 to 2016." Social Forces 96(3):1243-73.

Thornton, Arland. 1989. "Changing Attitudes toward Family Issues in the United States ". Journal of Marriage and the Family 51(4):873-93.

Thornton, Arland. 2001. "The Developmental Paradigm, Reading History Sideways, and Family Change." Demography 38(4):449-65.

Thornton, Arland and Linda Young-DeMarco. 2001. "Four Decades of Trends in Attitudes toward Family Issues in the United States: The 1960s through the 1990s." Journal of Marriage and Family 63(4):1009-37.

Thornton, Arland, Ronald Freedman and william G. Axinn. 2002. "Intergenerational Panel Study of Parents and Children." Pp. 315-44 in Looking at Lives: American Longitudinal Studies 
of the Twentieth Century, edited by E. Phelps, F. F. Furstenberger Jr. and A. Colby. New York: Russell Sage Foundation.

Thornton, Arland. 2005. Reading History Sideways: The Fallacy and Enduring Impact of the Developmental Paradigm on Family Life. Chicago: The University of Chicago Press.

Thornton, Arland, Georgina Binstock and Dirgha J. Ghimire. 2008. "International Dissemination of Ideas About Development and Family Change." Pp. 19-44 in International Family Change: Ideational Perspectives, edited by R. Jayakody, A. Thornton and W. G. Axinn. New York, NY: Lawrence Erlbaum.

Thornton, Arland and Dimiter Philipov. 2009. "Sweeping Changes in Marriage, Cohabitation and Childbearing in Central and Eastern Europe: New Insights from the Developmental Idealism Framework." European Journal of Population 25(2):123-56.

Thornton, Arland, Georgina Binstock, Mohammad Jalal Abbasi-Shavazi, Dirgha Ghimire, Arjan Gjonca, Attila Melegh, Colter Mitchell, Mansoor Moaddel, Yu Xie and Li-shou Yang. 2012a. "Knowledge and Beliefs About National Development and Developmental Hierarchies: The Viewpoints of Ordinary People in Thirteen Countries." Social Science Research 41(5):1053-68.

Thornton, Arland, Georgina Binstock, Kathryn M. Yount, Mohammad Jalal Abbasi-Shavazi, Dirgha J. Ghimire and Yu Xie. 2012b. "International Fertility Change: New Data and Insights from the Developmental Idealism Framework." Demography 49(2):677-98. Thornton, Arland, Dirgha J. Ghimire and Colter Mitchell. 2012. "The Measurement and Prevalence of an Ideational Model of Family and Economic Development in Nepal." Population Studies 66(3):329-45. 
Thornton, Arland, Rachael S. Pierotti, Linda Young-DeMarco and Susan Watkins. 2014.

"Developmental Idealism and Cultural Models of the Family in Malawi." Population Research and Policy Review 33(5):693-716.

Thornton, Arland, Shawn F. Dorius and Jeffrey Swindle. 2015. "Developmental Idealism: The Cultural Foundations of World Development Programs." Sociology of Development $1(2): 277-320$.

Thornton, Arland and Yu Xie. 2016. "Developmental Idealism in China." Chinese Journal of Sociology 2(4):483-96.

Van de Kaa, Dirk J. 1987. "Europe's Second Demographic Transition." Population Bulletin 42(1):1-57.

Veroff, Joseph, Elizabeth Couvan and Richard A. Kulka. 1981. The Inner American. New York: Basic Books.

Watkins, Susan C. and Dennis Hodgson. 2019. "Developmental Idealism, the International Population Movement, and the Transformation of Population Ideology in Kenya." Sociology of Development 5(3):229-47.

Yount, Kathryn M. and Hoda Rashad, eds. 2008. Family in the Middle East: Ideational Change in Egypt, Iran, and Tunisia. London: Routledge.

Yount, Kathryn M., Arland Thornton, Linda Young-DeMarco and Shilpa N. Patel. 2017. "Lay Accounts of "Modern" and "Traditional" Family in Greater Cairo: A Test of Developmental Models of Family Life." Pp. 133-70 in Values, Political Action, and Change in the Middle East and the Arab Spring edited by M. Moaddel and M. J. Gelfand. Oxford: Oxford University Press.

Yu, Jia and Yu Xie. 2015. "Cohabitation in China: Trends and Determinants." Population and Development Review 41(4):607-28. 
Zaidi, B. and S. P. Morgan. 2017. "The Second Demographic Transition Theory: A Review and Appraisal." Annual Review of Sociology 43:473-92. 
Figure 1. Women's (solid lines) and men's (dashed lines) attitudes towards gendered decision-making (top panel) and division of labor within families (bottom panel), 1962-2018.
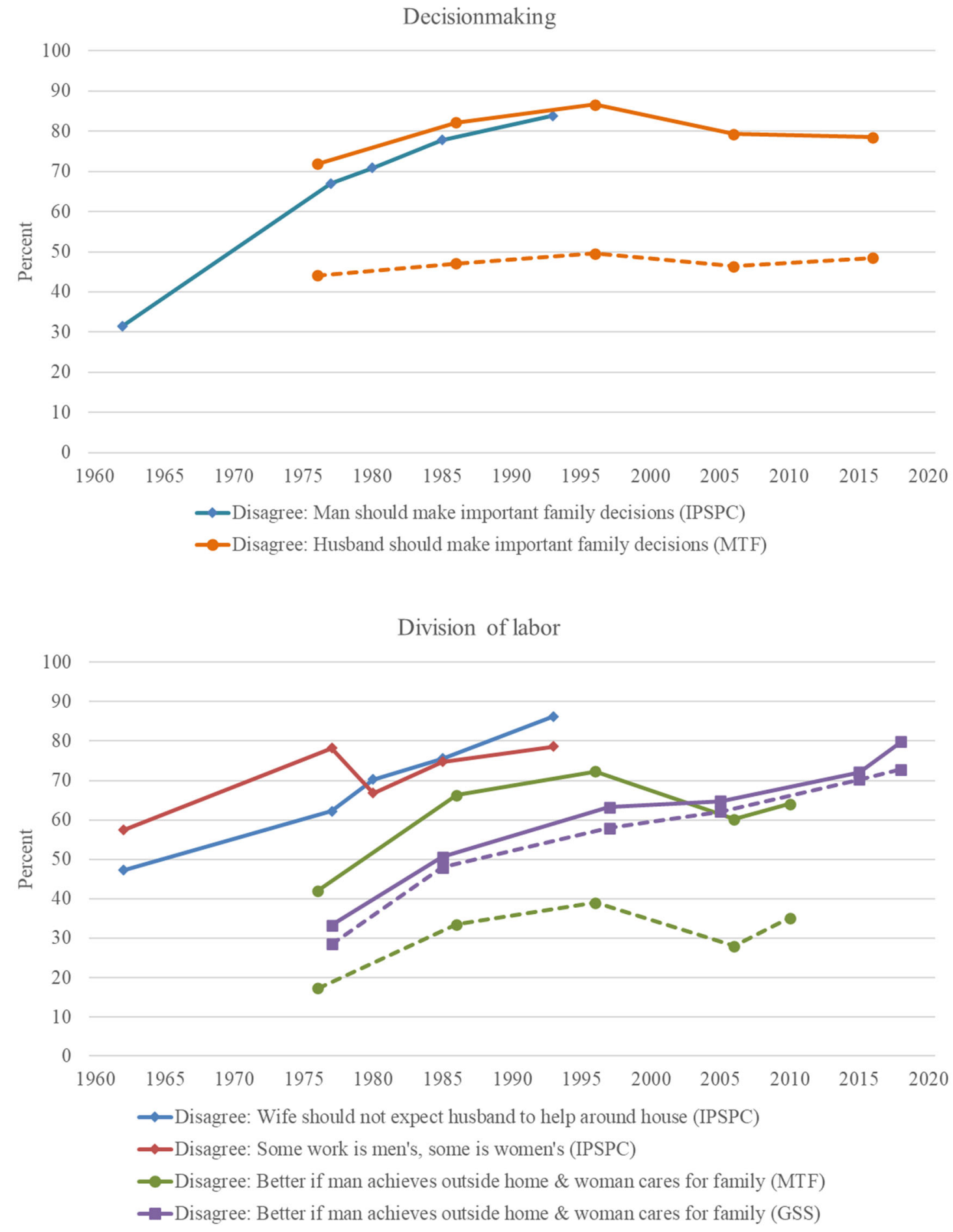

Sources: Intergenerational Panel Study of Parents and Children (IPSPC) 1962, 1977, 1980, 1993; Monitoring the Future (MTF) 1976-77, 1986-87, 1996-97, 2006-07, 2016-17; and General Social Survey (GSS) 1977, 1986-86, 1996/98, 2004/06, 2014/16, 2018. 
Figure 2. Women's (solid lines) and men's (dashed lines) beliefs about the consequences of women combining motherhood with work outside the home, 1976-2018.

Agree: Working mothers secure warm child relationships

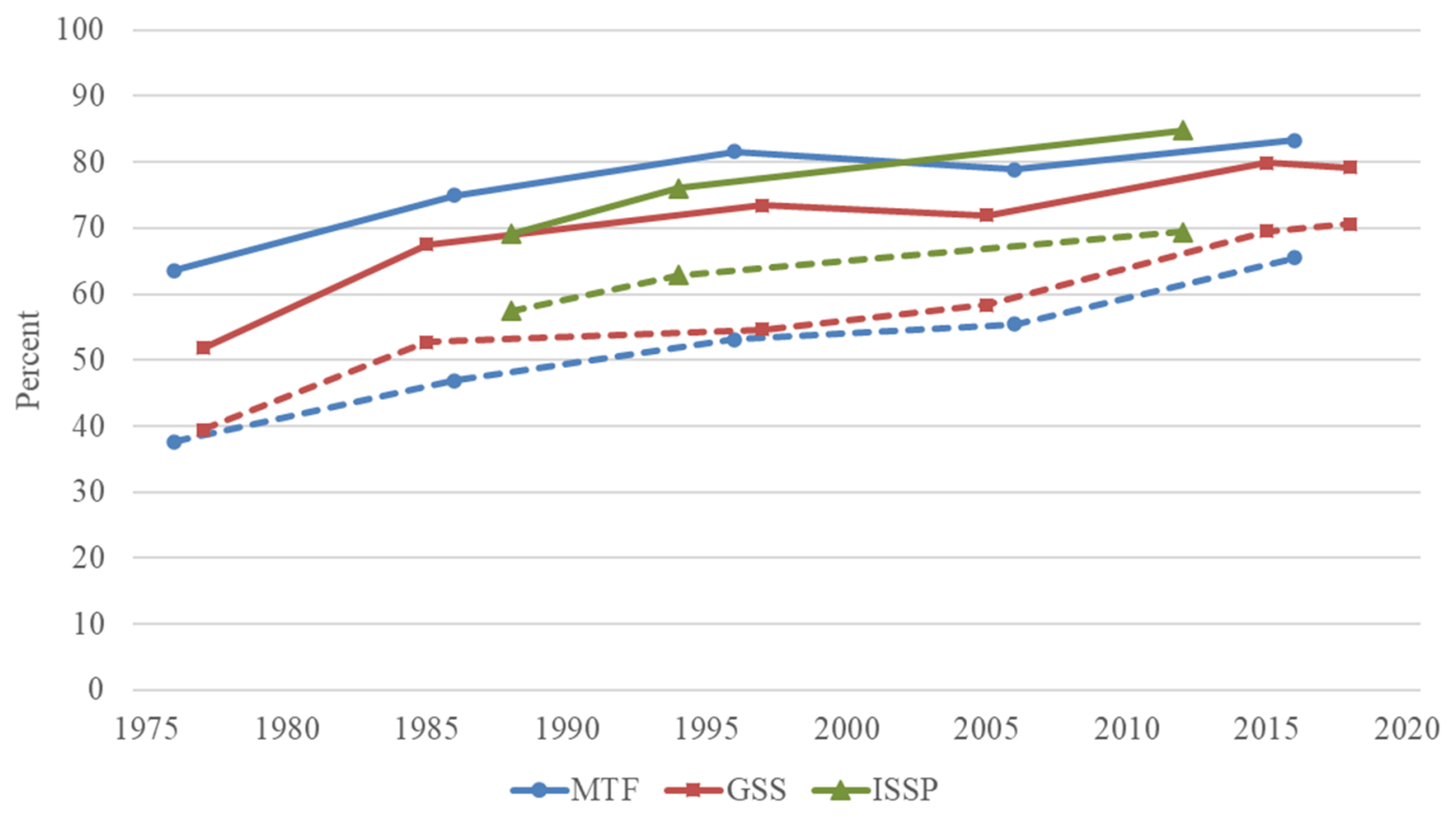

Disagree: Preschool child likely suffers if mother works

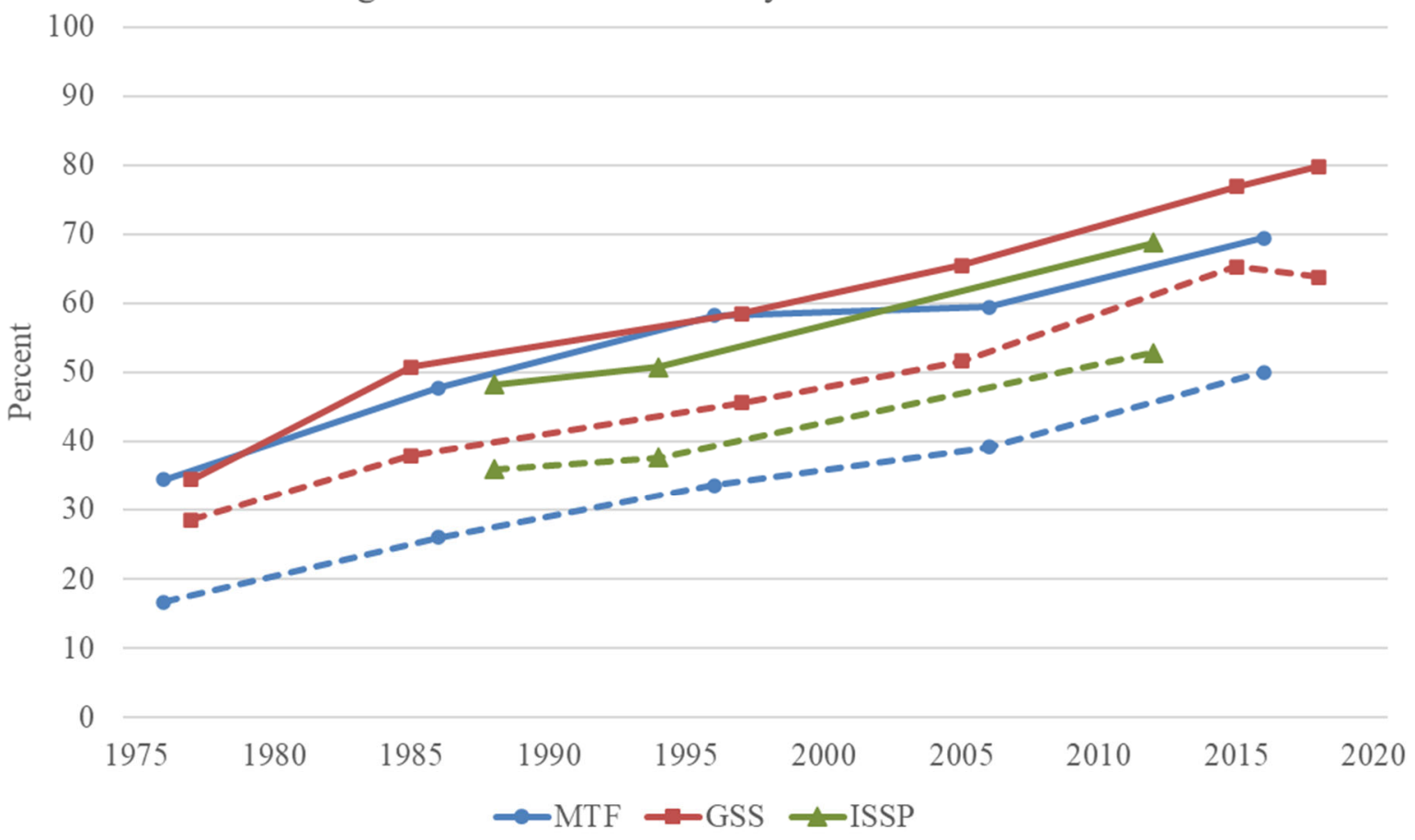

Sources: Monitoring the Future (MTF) 1976-77, 1986-87, 1996-97, 2006-07, 2016-17; General Social Survey (GSS) 1977, 1985-86, 1996/98, 2004/06, 2014/16, 2018; and International Social Science Program (ISSP) 1988, 1994, 2012. 
Figure 3. Women's (solid lines) and men's (dashed lines) attitudes and beliefs about marriage, 19762017.
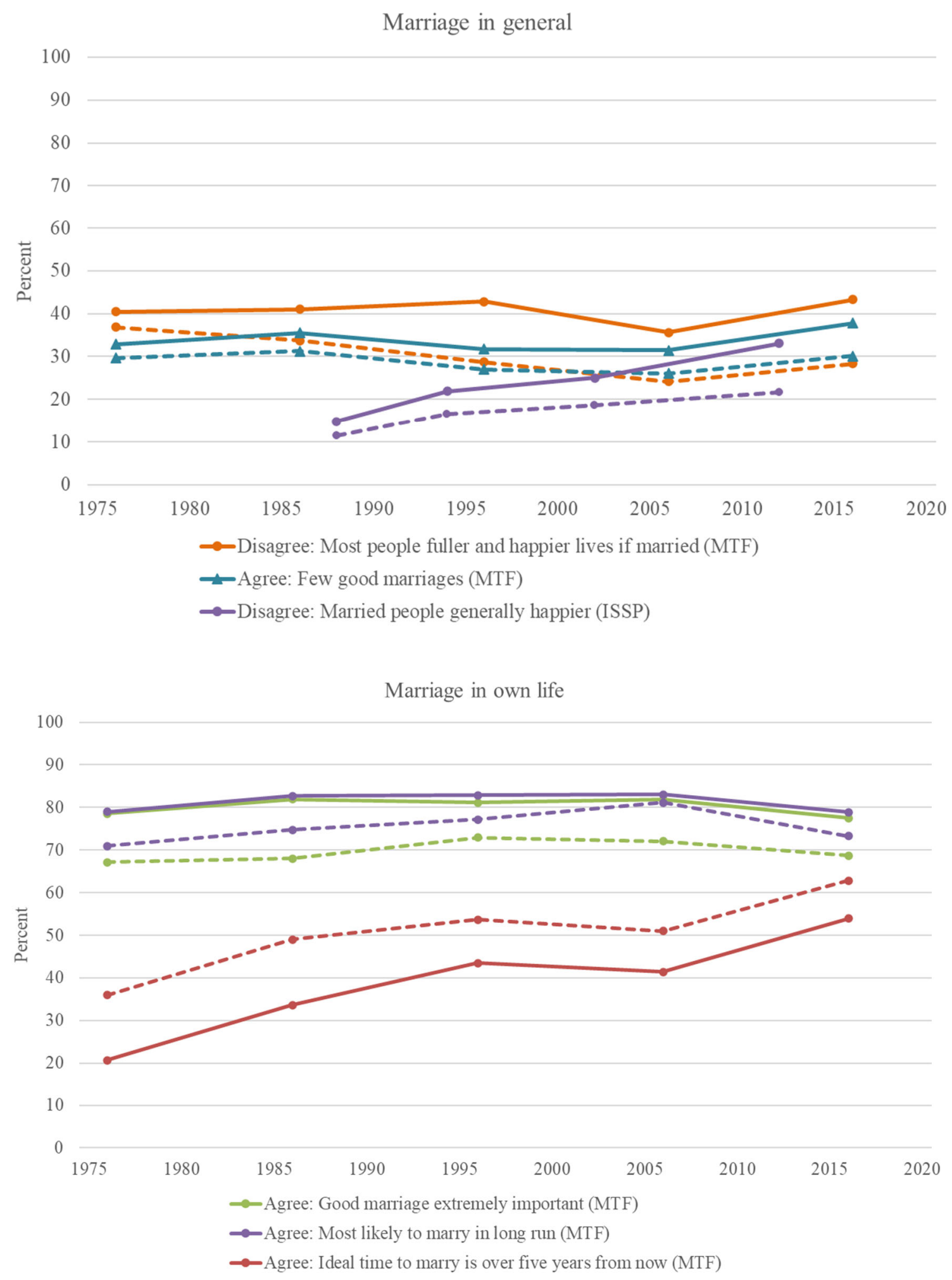

Sources: Monitoring the Future (MTF) 1976-77, 1986-87, 1996-97, 2016-17 and International Social Science Project (ISSP) 1988, 1994, 2002, 2012. 
Figure 4. Women's (solid lines) and men's (dashed lines) attitudes toward childbearing and parenthood, 1962-2017.
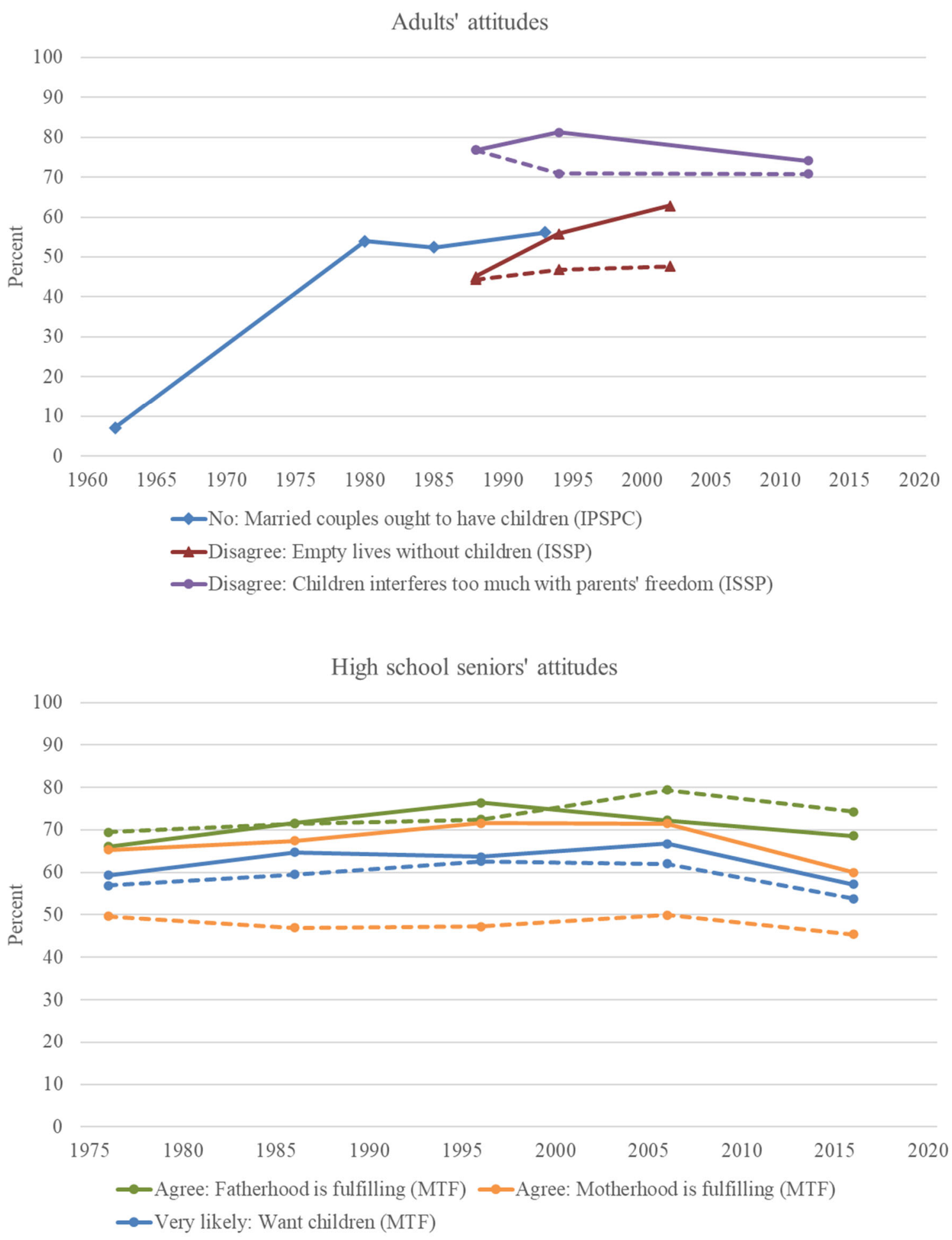

Sources: Intergenerational Panel Study of Parents and Children (IPSPC) 1962, 1980, 1985, and 1993; International Social Science Project (ISSP) 1988, 1994, 2002, 2012; and Monitoring the Future (MTF) 1976-77, 1986-87, 1996-97, 2006-07, and 2016-17. 
Figure 5. The ideal number of children according to women (solid lines) and men (dashed lines), including percentages viewing exact numbers as ideal and overall means, 1972-2018.

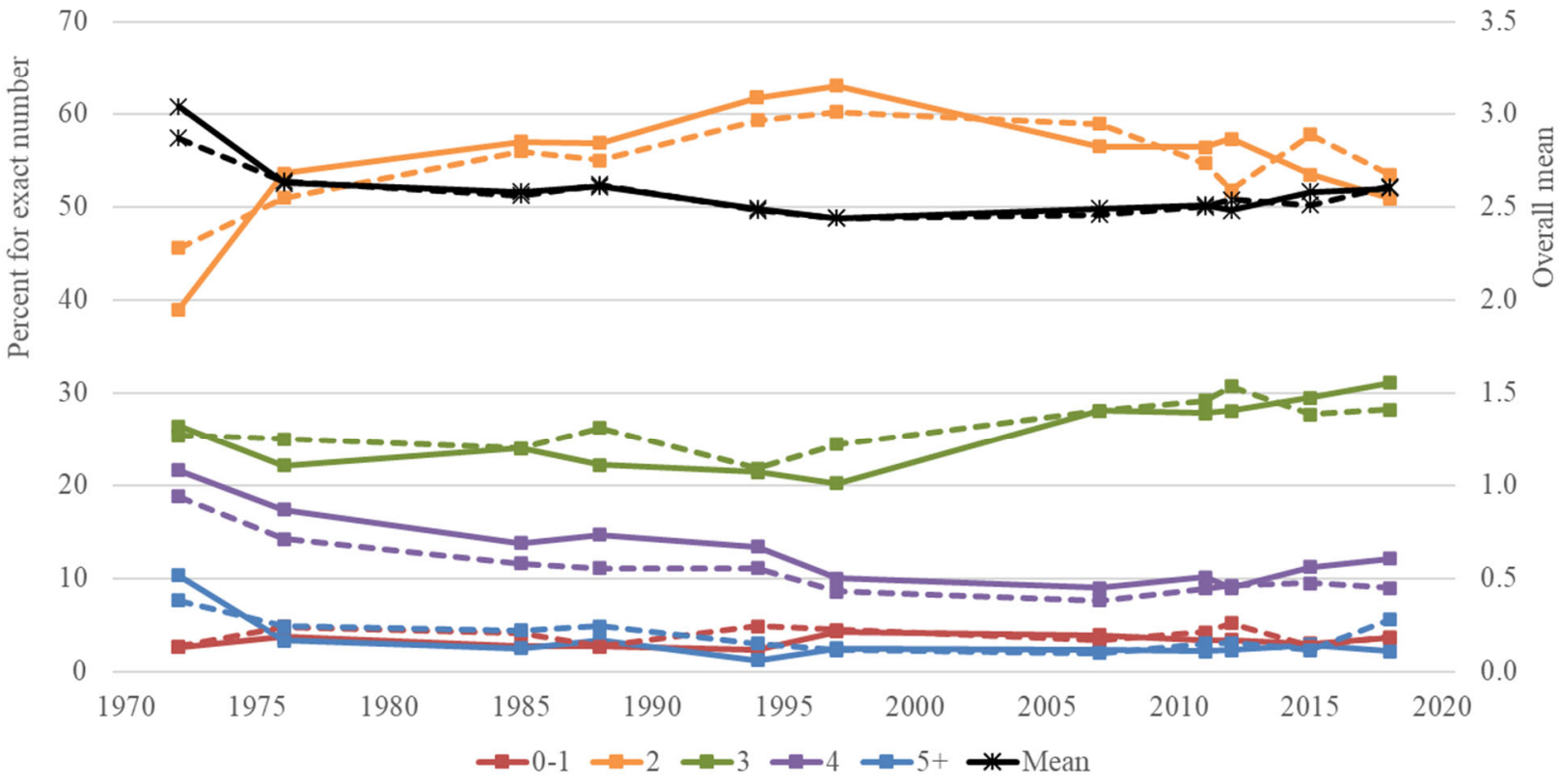

Sources: General Social Survey (GSS) 1972, 1976-77, 1996/98, 2014/16, 2018 and International Social Science Project (ISSP) 1988, 1994, 2012. 
Figure 6. Women's (solid lines) and men's (dashed lines) attitudes and beliefs about divorce and the durability of marriage, 1962-2017.

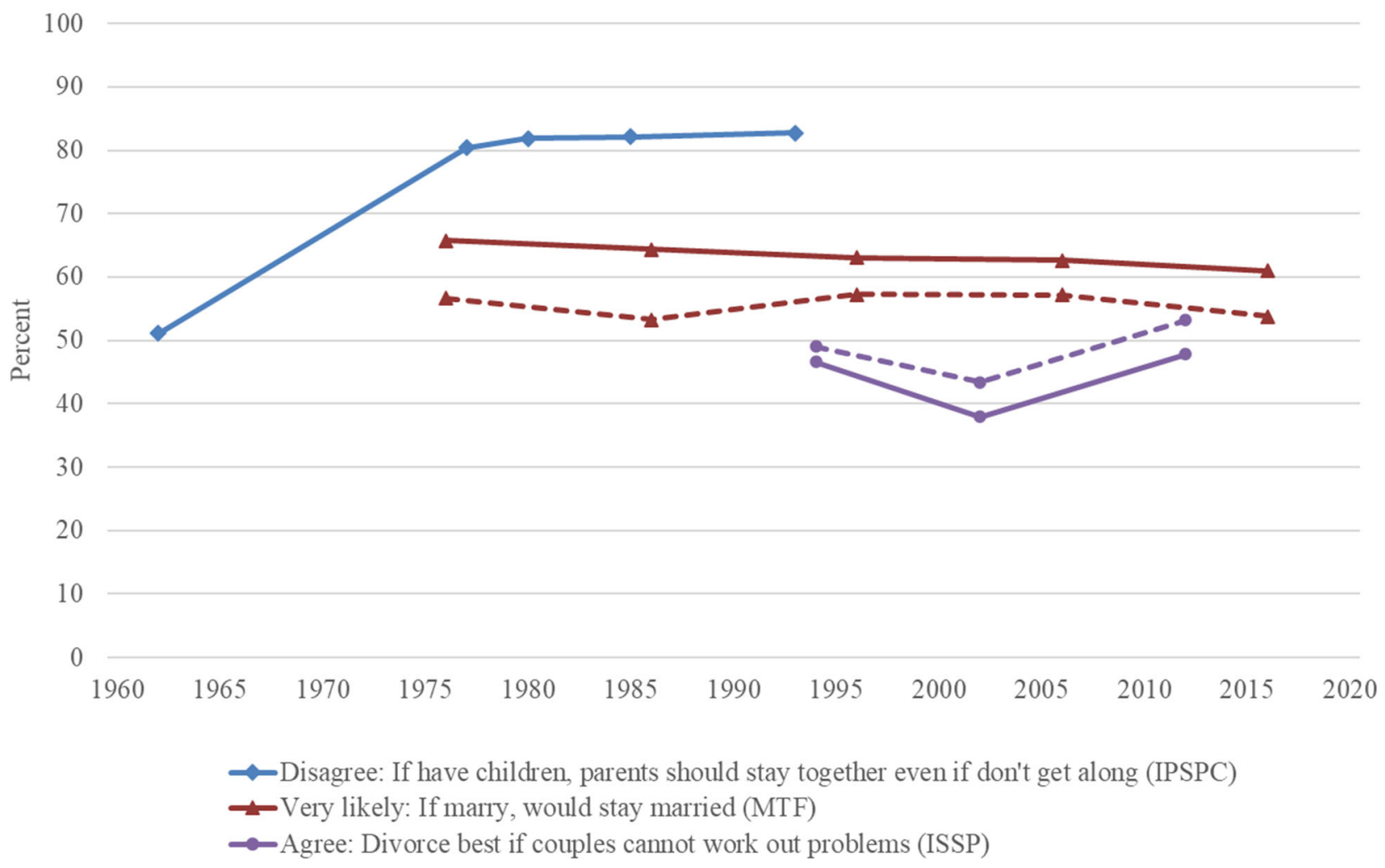

Sources: Intergenerational Panel Study of Parents and Children (IPSPC) 1962, 1977, 1980, 1985, 1993; Monitoring the Future (MTF) 1976-77, 1986-87, 1996-97, 2006-07, 2016-17; and International Social Science Project (ISSP) 1994, 2002, 2012. 
Figure 7. Women's (solid lines) and men's (dashed lines) attitudes towards heterosexual sex outside marriage, 1976-2018.
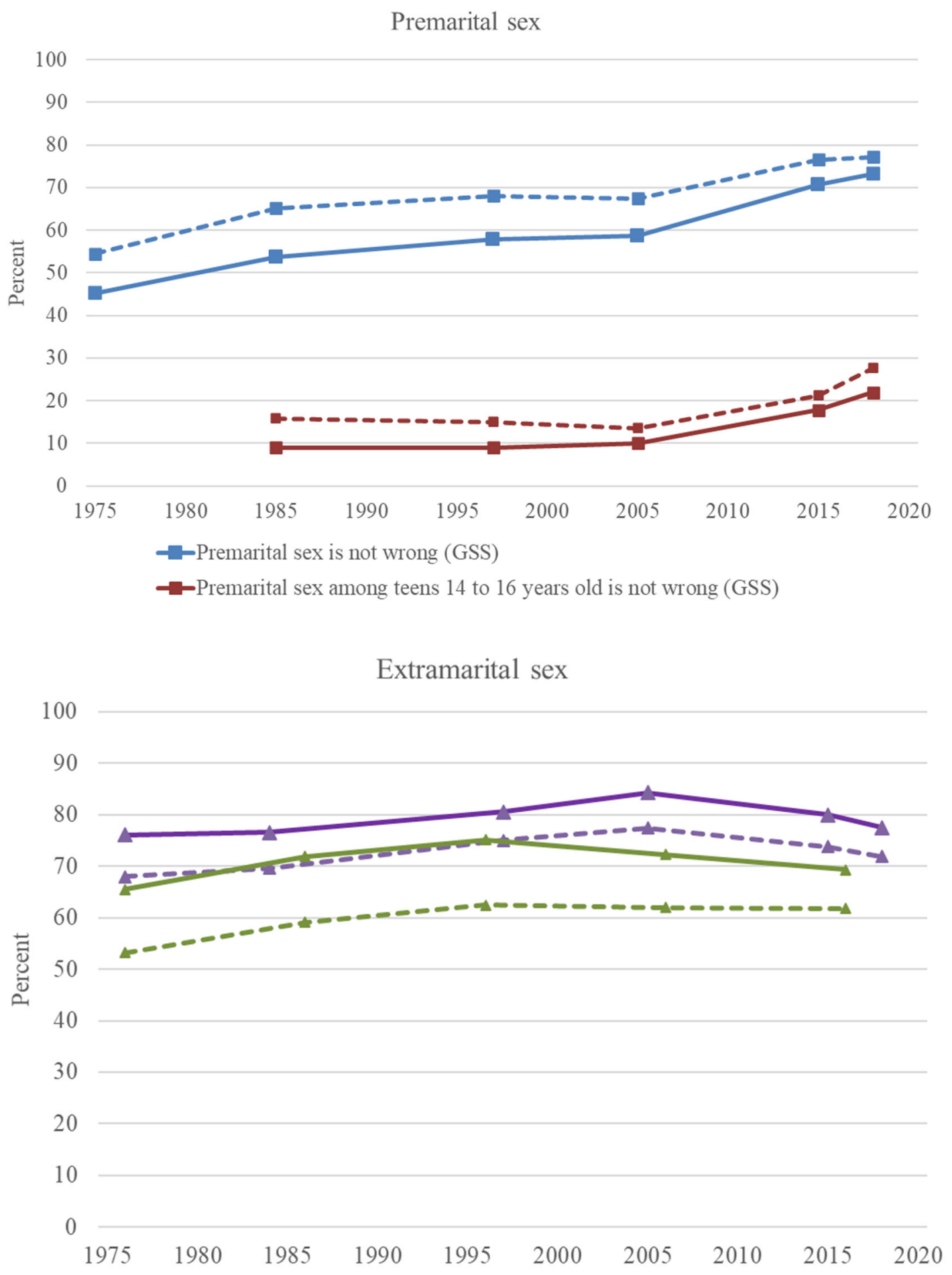

$\neg$ Extramarital sex is wrong (GSS) $\simeq$ Disagree: One partner is too restrictive (MTF)

Sources: General Social Survey (GSS) 1976-77, 1984-85, 1996/98, 2014/16, 2018 and Monitoring the Future (MTF) 1976-77, 1986-87, 1996-97, 2006-07, 2016-17. 
Figure 8. Women's (solid lines) and men's (dashed lines) attitudes towards cohabitation (top panel), as well as nonmarital childbearing and childrearing (bottom panel), 1976-2017.
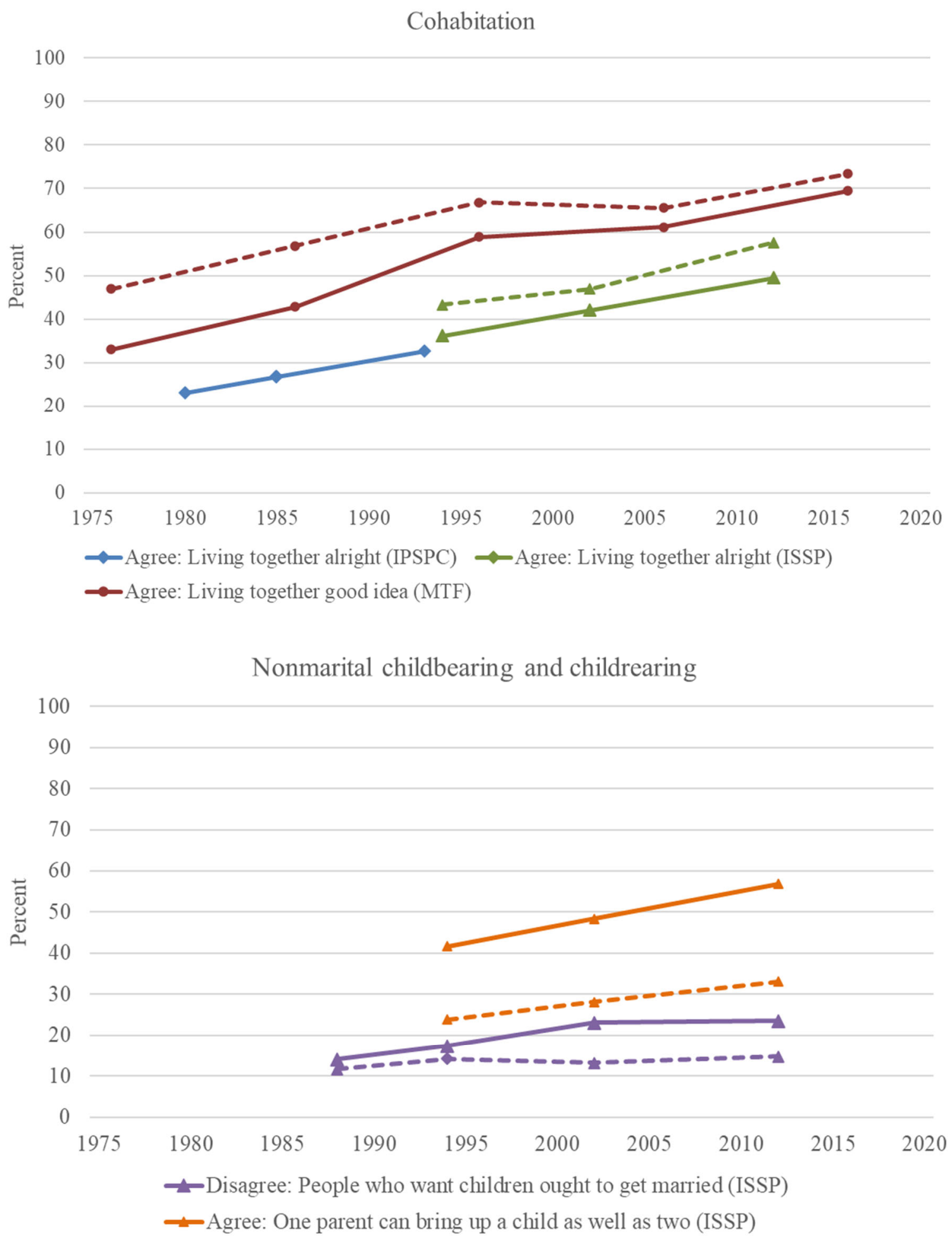

Sources: Intergenerational Panel Study of Parents and Children (IPSPC) 1980, 1985, 1993; International Social Science Project (ISSP) 1988, 1994, 2002, 2012; and Monitoring the Future (MTF) 1976-77, 1986-87, 1996-97, 2006-07, 2016-17. 
Figure 9. Women's (solid lines) and men's (dashed lines) attitudes towards same-sex relations and marriage, 1977-2018.

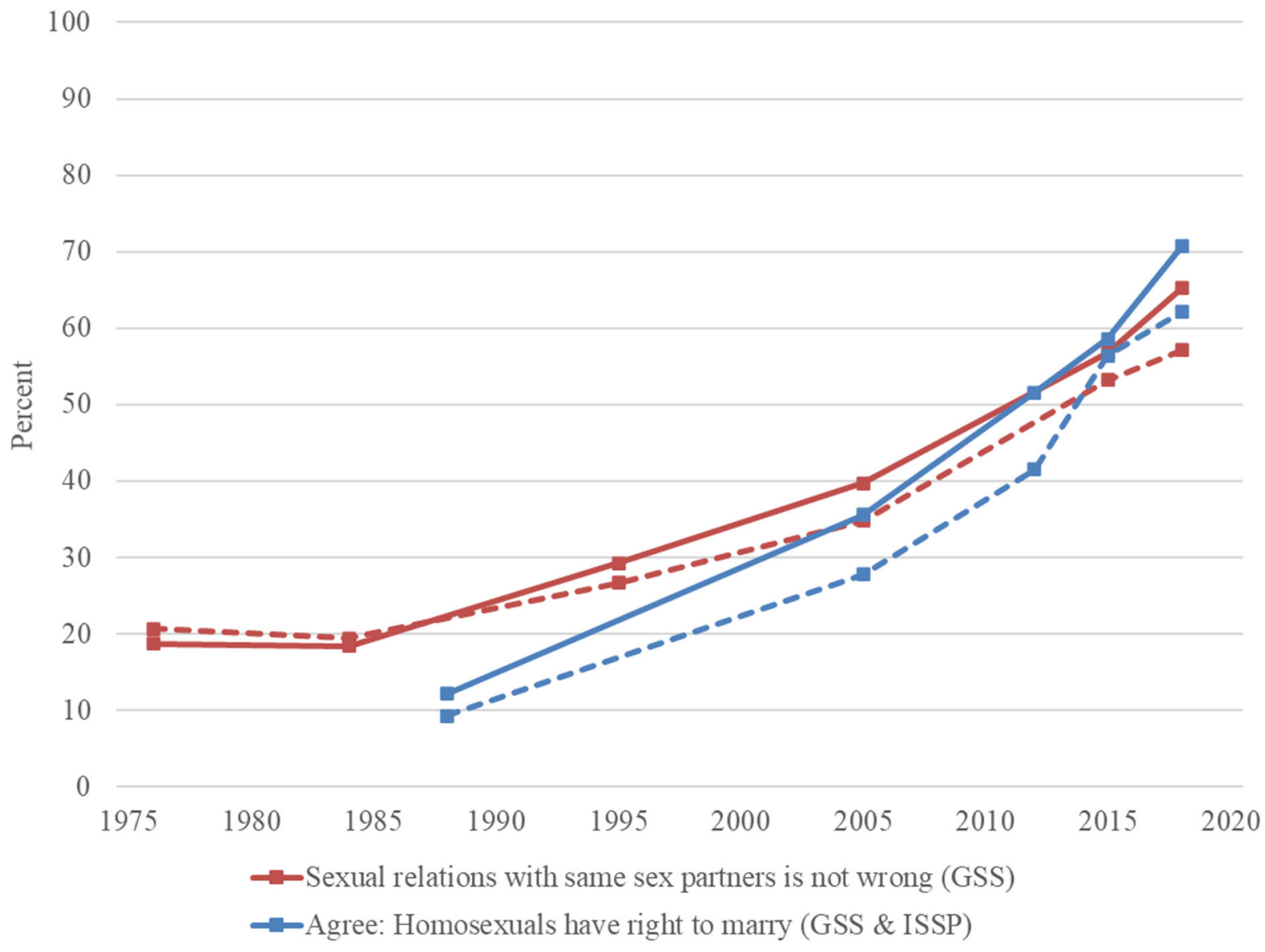

Sources: General Social Survey (GSS) 1976-77, 1984-85, 1994/96, 2004/06, 2014/16, 2018 and International Social Science Project (ISSP) 1988, 2012. 


\section{Online Appendix A: Tables with Point Estimates and Unweighted Sample Sizes for All Items}

Table 1. Percentage of Respondents with Egalitarian Gender Attitudes ${ }^{\text {a }}$

A. Intergenerational Panel Study of Parents and Children (IPS)

\begin{tabular}{lccccc|ccc|cccc} 
& \multicolumn{1}{c}{ Mothers } & \multicolumn{4}{c}{ Daughters } & \multicolumn{4}{c}{ Sons } \\
& 1962 & 1977 & 1980 & 1985 & 1993 & 1980 & 1985 & 1993 & 1980 & 1985 & 1993 \\
\hline & & & & & & & & & & & \\
Decisions & 31.5 & $67.0^{*}$ & $70.9^{*}$ & $77.8^{*}$ & $83.9^{*}$ & 66.7 & $85.0^{*}$ & $89.5^{*}$ & 45.7 & $64.6^{*}$ & $77.9^{*}$ \\
Women Active & 44.1 & $58.6^{*}$ & $65.1^{*}$ & $72.3^{*}$ & $76.8^{*}$ & 72.2 & $89.2^{*}$ & $93.1^{*}$ & 73.0 & $85.2^{*}$ & $92.6^{*}$ \\
Men/Women's Work & 57.4 & $78.2^{*}$ & $66.8^{*}$ & $74.7^{*}$ & $78.6^{*}$ & 69.3 & $79.7^{*}$ & $83.8^{*}$ & 52.9 & $63.4^{*}$ & $72.5^{*}$ \\
Housework & 47.2 & $62.2^{*}$ & $70.3^{*}$ & $75.6^{*}$ & $86.2^{*}$ & 73.3 & $86.3^{*}$ & $95.1^{*}$ & 76.8 & $89.8^{*}$ & $95.4^{*}$ \\
Relations/Working Mother & --- & 64.8 & $79.2^{*}$ & $75.2^{*}$ & 78.0 & 74.3 & 77.5 & 79.2 & 66.7 & 69.2 & 71.5 \\
Men Work/Women Home & --- & 34.3 & 38.9 & $47.9^{*}$ & 47.8 & 57.5 & $65.7^{*}$ & 69.0 & 47.8 & $62.1^{*}$ & $68.2^{*}$ \\
Women Happier Home & --- & 66.8 & 73.0 & $70.8^{*}$ & 70.5 & 78.9 & 82.4 & $80.9^{*}$ & 72.0 & 76.8 & $72.8^{*}$ \\
Husband/Wife Career & --- & 48.4 & 53.8 & $63.3^{*}$ & $70.7^{*}$ & 80.4 & $88.0^{*}$ & $91.7^{*}$ & 76.3 & $86.3^{*}$ & 88.0 \\
$\mathrm{~N}^{\mathrm{b}}$ & 801 & 801 & 801 & 801 & 801 & 408 & 408 & 408 & 393 & 393 & 393 \\
\hline
\end{tabular}

\section{B. Monitoring the Future (MTF)}

\begin{tabular}{lccccc|cccccc} 
& \multicolumn{3}{c}{ Women } & \multicolumn{9}{c}{ Men } \\
& $76-77$ & $86-87$ & $96-97$ & $06-07$ & $16-17$ & $76-77$ & $86-87$ & $96-97$ & $06-07$ & $16-17$ \\
\hline & & & & & & & & & & \\
Decisions & 71.9 & $82.2^{*}$ & $86.6^{*}$ & $79.3^{*}$ & 78.5 & 44.1 & $47.1^{*}$ & $49.6^{*}$ & 46.4 & 48.5 \\
Housework & 72.1 & $78.6^{*}$ & 77.6 & --- & --- & 67.1 & $69.6^{*}$ & $67.4^{*}$ & --- & --- \\
Relations/Working Mother & 63.6 & $74.9^{*}$ & $81.6^{*}$ & 78.9 & $83.3^{*}$ & 37.6 & $46.9^{*}$ & $53.1^{*}$ & 55.4 & $65.5^{*}$ \\
Preschool Child Suffer & 34.5 & $47.8^{*}$ & $58.2^{*}$ & 59.4 & $69.4^{*}$ & 16.7 & $26.0^{*}$ & $33.6^{*}$ & $39.2^{*}$ & $50.0^{*}$ \\
Men Achve/Women Home & 42.1 & $66.3^{*}$ & $72.3^{*}$ & $60.2^{*}$ & 64.0 & 17.3 & $33.5^{*}$ & $39.0^{*}$ & $28.0^{*}$ & $35.1^{*}$ \\
Job \& Relations with Husband & 83.5 & 84.8 & 85.5 & --- & --- & 63.1 & $64.6^{*}$ & $67.3^{*}$ & --- & --- \\
Job Allows Wife Develop & 87.7 & $91.4^{*}$ & $88.2^{*}$ & -- & -- & 72.3 & $77.4^{*}$ & $70.3^{*}$ & --- & --- \\
$\mathrm{N}^{\mathrm{b}}$ & 3423 & 3264 & 2484 & 2468 & 1900 & 3290 & 3020 & 2351 & 2202 & 1950 \\
\hline
\end{tabular}




\section{General Social Survey (GSS)}

\begin{tabular}{|c|c|c|c|c|c|c|c|c|c|c|c|c|}
\hline & \multicolumn{6}{|c|}{ Women } & \multicolumn{6}{|c|}{ Men } \\
\hline & 1977 & $85-86$ & $96 / 98$ & $04 / 06$ & $14 / 16$ & 2018 & 1977 & $85-86$ & $96 / 98$ & $04 / 06$ & $14 / 16$ & 2018 \\
\hline Relations/Working Mother & 51.8 & $67.5^{*}$ & $73.4^{*}$ & 71.9 & $79.9 *$ & 79.2 & 39.4 & $52.7 *$ & 54.6 & 58.3 & $69.5^{*}$ & 70.6 \\
\hline Husband/Wife Career & 34.6 & $59.4^{*}$ & $77.4^{*}$ & --- & --- & & 42.8 & $58.9 *$ & $75.0 *$ & --- & --- & \\
\hline Preschool Child Suffer & 34.5 & $50.8 *$ & $58.5^{*}$ & $65.5^{*}$ & $76.9 *$ & 79.8 & 25.4 & $38.0 *$ & $45.6^{*}$ & $51.6^{*}$ & $65.3 *$ & 63.8 \\
\hline Men Achieve/Women Home & 33.3 & $50.6^{*}$ & $63.2 *$ & 64.8 & $72.1 *$ & $79.8^{*}$ & 28.5 & $48.0^{*}$ & $57.9 *$ & $62.1 *$ & $70.3 *$ & 72.8 \\
\hline Married Women Work & 63.8 & $79.7 *$ & 81.3 & --- & --- & & 68.0 & $81.6 *$ & 82.1 & --- & --- & \\
\hline $\mathrm{N}^{\mathrm{b}}$ & 734 & 1547 & 2237 & 1411 & 1758 & 774 & 602 & 1196 & 1721 & 1146 & 1435 & 624 \\
\hline
\end{tabular}

\section{International Social Science Program (ISSP) ${ }^{c}$}

\begin{tabular}{|c|c|c|c|c|c|c|c|c|}
\hline & \multicolumn{4}{|c|}{ Women } & \multicolumn{4}{|c|}{ Men } \\
\hline & 1988 & 1994 & 2002 & 2012 & 1988 & 1994 & 2002 & 2012 \\
\hline Relations/Working Mother & 69.1 & $76.0 *$ & $---x$ & $84.8 *$ & 57.4 & $62.9 *$ & $---\mathrm{X}$ & $69.4 *$ \\
\hline Preschool Child Suffer & 48.2 & 50.8 & --- & $68.8 *$ & 36.0 & 37.7 & --- & $52.8 *$ \\
\hline Family Life Suffers & 50.8 & 52.1 & --- & $60.8 *$ & 46.2 & 46.2 & --- & $52.4^{*}$ \\
\hline $\mathrm{N}^{\mathrm{b}}$ & 722 & 793 & & 649 & 539 & 546 & & 540 \\
\hline
\end{tabular}

* Asterisks indicate that the difference between that year and the earlier year is statistically significant at the .05 level. Differences of means tests were used in the Intergenerational Panel Study. Differences of proportions tests were used in Monitoring the Future and the General Social Survey. For the International Social Science Program, chi square tests were used.

a The question wording and coding of responses are provided in the appendix.

b The number of cases for all studies is the unweighted N. However, for Monitoring the Future, General Social Survey, and International Social Science Program the percentages are estimated using the weights provided by the data collection organizations.

c Responses for 2002 ISSP not shown due to non-comparable answer categories offered that year. 
Table 2. Distribution of Attitudes Toward Marriage ${ }^{a}$

A. Intergenerational Panel Study of Parents and Children (IPS)

\begin{tabular}{lccc|ccc|cccc} 
& \multicolumn{3}{c}{ Mothers } & \multicolumn{4}{c}{ Daughters } & \multicolumn{3}{c}{ Sons } \\
& 1980 & 1985 & 1993 & 1980 & 1985 & 1993 & 1980 & 1985 & 1993 \\
\hline & & & & & & & & & \\
Married Happier (Disagree) & 35.0 & $31.0^{*}$ & $36.6^{*}$ & 47.1 & 45.1 & 47.9 & 36.1 & 37.9 & $40.7^{*}$ \\
Few Good Marriages (Agree) & 35.5 & $30.7^{*}$ & $38.7^{*}$ & 36.5 & $27.2^{*}$ & $33.9^{*}$ & 32.7 & $25.8^{*}$ & $28.1^{*}$ \\
Better Married (Disagree) & 68.5 & 67.1 & $73.1^{*}$ & 72.0 & 73.9 & 75.5 & 59.1 & 62.5 & $68.8^{*}$ \\
Better Single (Agree) & 08.8 & 09.7 & 10.3 & 22.7 & $13.5^{*}$ & 10.8 & 34.0 & $20.4^{*}$ & $12.5^{*}$ \\
N & 801 & 801 & 801 & 408 & 408 & 408 & 393 & 393 & 393 \\
\hline
\end{tabular}

B. International Social Science Project (ISSP)

\begin{tabular}{|c|c|c|c|c|c|c|c|c|}
\hline & \multicolumn{4}{|c|}{ Women } & \multicolumn{4}{|c|}{ Men } \\
\hline & 1988 & 1994 & 2002 & 2012 & 1988 & 1994 & 2002 & 2012 \\
\hline Married Happier (disagree) & 14.8 & $21.9 *$ & 25.0 & $33.1 *$ & 11.4 & $16.6^{*}$ & 18.6 & $21.6^{*}$ \\
\hline $\mathrm{N}$ & 722 & 793 & 616 & 646 & 539 & 546 & 448 & 539 \\
\hline
\end{tabular}

\section{Monitoring the Future (MTF)}

\begin{tabular}{lccccc|ccccc} 
& \multicolumn{9}{c}{ Women } & \multicolumn{1}{c}{ Men } \\
& $76-77$ & $86-87$ & $96-97$ & $06-07$ & $16-17$ & $76-77$ & $86-87$ & $96-97$ & $06-07$ & $16-17$ \\
\hline $\begin{array}{l}\text { Married Happier } \\
\begin{array}{l}\text { (Disagree) } \\
\text { Few Good Marriages } \\
\text { (Agree) }\end{array}\end{array}$ & 40.5 & 41.0 & $42.8^{*}$ & $35.6^{*}$ & $43.3^{*}$ & 36.9 & $33.7^{*}$ & $28.7^{*}$ & $24.2^{*}$ & 28.3 \\
$\mathrm{~N}$ & $35.5^{*}$ & $31.7^{*}$ & 31.5 & $37.8^{*}$ & 29.7 & $31.3^{*}$ & $27.0^{*}$ & 26.1 & $30.1^{*}$ \\
& 3423 & 3200 & 2356 & 2197 & 1730 & 3290 & 2247 & 2200 & 2056 & 1692 \\
\hline
\end{tabular}


D. Monitoring the Future (MTF)

\begin{tabular}{lccccc|cccccc} 
& \multicolumn{1}{c}{ Women } & \multicolumn{7}{c}{ Men } \\
& $76-77$ & $86-87$ & $96-97$ & $06-07$ & $16-17$ & $76-77$ & $86-87$ & $96-97$ & $06-07$ & $16-17$ \\
\hline $\begin{array}{l}\text { Importance Good Marriage } \\
\quad \text { (Extremely Important) }\end{array}$ & 78.5 & $81.9^{*}$ & 81.1 & 81.8 & $77.5^{*}$ & 67.1 & 68.0 & $72.9^{*}$ & 72.1 & 68.7 \\
$\mathrm{~N}$ & 3423 & 3191 & 2442 & 2398 & 1951 & 3290 & 3011 & 2198 & 2178 & 1820 \\
& & & & & & & & & & \\
Choice about Marriage & & & & & & & & & & \\
$\quad($ Getting married) & 79.0 & $82.7 *$ & 82.9 & 83.0 & $78.9^{*}$ & 70.9 & $74.7^{*}$ & $77.2^{*}$ & $81.1^{*}$ & $73.3^{*}$ \\
$\mathrm{~N}$ & 3423 & 3207 & 2449 & 2358 & 1841 & 3290 & 2980 & 2263 & 2131 & 1835 \\
& & & & & & & & & & \\
Ideal Time to Marry & & & & & & & & & & \\
$\quad$ (Over 5 years from now) & 20.7 & $33.6^{*}$ & $43.5^{*}$ & 41.4 & $53.9^{*}$ & 36.0 & $49.0^{*}$ & 53.7 & 51.0 & $62.8^{*}$ \\
$\mathrm{~N}$ & 3423 & 3138 & 2245 & 2244 & 1640 & 3290 & 2819 & 2041 & 1959 & 1704 \\
\hline
\end{tabular}

* Asterisks indicate that the difference between that year and the earlier year is statistically significant at the .05 level. See Table 1 for statistical significance tests used.

a The question wording and coding of responses are provided in the appendix. 
Table 3. Distributions of Attitudes Towards Childbearing and Parenthood ${ }^{\mathrm{a}}$

A. Intergenerational Panel Study of Parents and Children (IPS)

\begin{tabular}{lcccc|ccc|ccc} 
& \multicolumn{2}{c}{ Mothers } & \multicolumn{9}{c}{ Daughters } & \multicolumn{3}{c}{ Sons } \\
& 1962 & 1980 & 1985 & 1993 & 1980 & 1985 & 1993 & 1980 & 1985 & 1993 \\
\hline \multirow{2}{*}{ All Couples Parents } & & & & & & & & & & \\
Yes & 84.5 & $42.5^{*}$ & 42.5 & 41.1 & 36.3 & 32.8 & $21.9 *$ & 40.7 & 40.5 & $30.6^{*}$ \\
Depends & 08.4 & 03.5 & 05.1 & 02.8 & 05.9 & 03.2 & 04.2 & 05.6 & 04.8 & 04.8 \\
No & 07.1 & 54.0 & 52.4 & 56.1 & 57.8 & 64.0 & 73.9 & 53.7 & 54.7 & 64.5 \\
N & 801 & 801 & 801 & 801 & 408 & 408 & 408 & 393 & 393 & 393 \\
\hline
\end{tabular}

\section{B. International Social Science Project (ISSP )}

\begin{tabular}{|c|c|c|c|c|c|c|c|c|}
\hline & \multicolumn{2}{|c|}{ Women } & \multicolumn{6}{|c|}{ Men } \\
\hline & 1988 & 1994 & 2002 & 2012 & 1988 & 1994 & 2002 & 2012 \\
\hline $\begin{array}{l}\text { Empty Lives } \\
\text { (disagree/strongly disagree) }\end{array}$ & 45.1 & $55.8 *$ & $62.8 *$ & --- & 44.4 & 46.8 & 47.7 & --- \\
\hline $\mathrm{N}$ & 690 & 746 & 616 & & 527 & 518 & 448 & \\
\hline $\begin{array}{l}\text { Children Purpose Marriage } \\
\text { (disagree/strongly disagree) }\end{array}$ & 71.6 & 74.0 & --- & --- & 69.1 & $62.7 *$ & --- & --- \\
\hline $\mathrm{N}$ & 701 & 772 & & & 520 & 538 & & \\
\hline $\begin{array}{l}\text { Kids No Freedom } \\
\text { (agree/strongly agree) }\end{array}$ & 9.1 & $5.7 *$ & --- & $11.8^{*}$ & 9.8 & 11.0 & --- & 14.4 \\
\hline $\mathrm{N}$ & 718 & 770 & & 620 & 539 & 530 & & 520 \\
\hline
\end{tabular}




\section{Monitoring the Future (MTF )}

\begin{tabular}{|c|c|c|c|c|c|c|c|c|c|c|}
\hline & \multicolumn{5}{|c|}{ Women } & \multicolumn{5}{|c|}{ Men } \\
\hline & $76-77$ & $86-87$ & $96-97$ & 06-07 & $16-17$ & $76-77$ & $86-87$ & $96-97$ & 06-07 & $16-17$ \\
\hline $\begin{array}{l}\text { Fatherhood Fulfilling } \\
\text { (mostly agree or agree) }\end{array}$ & 66.1 & $71.6^{*}$ & $76.4 *$ & $72.2 *$ & $68.6^{*}$ & 69.4 & $71.5^{*}$ & 72.4 & $79.4 *$ & $74.3 *$ \\
\hline $\mathrm{N}$ & 3423 & 3197 & 2462 & 2416 & 1930 & 3290 & 3014 & 2314 & 2168 & 1819 \\
\hline $\begin{array}{l}\text { Motherhood Fulfilling } \\
\text { ( mostly agree or agree) }\end{array}$ & 65.3 & $67.4 *$ & $71.6^{*}$ & 71.5 & $60.0 *$ & 49.6 & $46.9 *$ & 47.2 & 49.9 & $45.4^{*}$ \\
\hline $\mathrm{N}$ & 3423 & 3180 & 2522 & 2408 & 2031 & 3290 & 2952 & 2322 & 2289 & 1951 \\
\hline $\begin{array}{l}\text { Likely Want Children } \\
\text { (very likely) }\end{array}$ & 59.3 & $64.7 *$ & 63.6 & 66.7 & $57.2 *$ & 56.9 & $59.5^{*}$ & $62.6^{*}$ & 62.0 & $53.8^{*}$ \\
\hline $\mathrm{N}$ & 3423 & 3100 & 2293 & 2246 & 1841 & 3290 & 2913 & 2173 & 2107 & 1873 \\
\hline
\end{tabular}

* Asterisks indicate that the difference between that year and the earlier year is statistically significant at the .05 level. See Table 1 for statistical significance tests used.

a The question wording and coding of responses are provided in the appendix. 


\section{Table 4. Distributions of Attitudes Toward Ideal Number of Children}

\section{A. General Social Survey}

\begin{tabular}{|c|c|c|c|c|c|c|c|c|c|c|c|c|c|c|}
\hline \multirow[b]{2}{*}{$\begin{array}{c}\text { Ideal Number } \\
\text { of Children }\end{array}$} & \multirow[b]{2}{*}{1972} & \multicolumn{4}{|c|}{ Women } & \multicolumn{8}{|c|}{ Men } & \multirow[b]{2}{*}{2018} \\
\hline & & $\begin{array}{c}1976- \\
1977\end{array}$ & $\begin{array}{c}1985- \\
1986\end{array}$ & $\begin{array}{c}1996 / \\
1998\end{array}$ & $\begin{array}{c}2006 / \\
2008\end{array}$ & $\begin{array}{l}2014 / \\
2016\end{array}$ & 2018 & 1972 & $\begin{array}{l}1976- \\
1977\end{array}$ & $\begin{array}{c}1985- \\
1986\end{array}$ & $\begin{array}{c}1996 / \\
1998\end{array}$ & $\begin{array}{c}2006 / \\
2008\end{array}$ & $\begin{array}{c}2014 / \\
2016\end{array}$ & \\
\hline None & 1.9 & 1.5 & 0.8 & 1.3 & 1.3 & 0.8 & 1.0 & 1.4 & 2.1 & 1.2 & 1.7 & 1.1 & 0.9 & 1.2 \\
\hline One & 0.7 & 2.2 & 1.9 & 3.0 & 2.6 & 2.2 & 2.6 & 1.3 & 2.7 & 2.9 & 2.8 & 2.2 & 1.8 & 2.5 \\
\hline Two & 39.0 & 53.6 & 57.0 & 63.0 & 56.5 & 53.5 & 50.9 & 45.6 & 51.0 & 56.0 & 60.2 & 58.9 & 57.8 & 53.5 \\
\hline Three & 26.4 & 22.1 & 24.0 & 20.2 & 28.1 & 29.5 & 31.1 & 25.4 & 25.0 & 24.0 & 24.4 & 28.1 & 27.7 & 28.2 \\
\hline Four & 21.6 & 17.4 & 13.8 & 10.0 & 9.0 & 11.2 & 12.1 & 18.8 & 14.2 & 11.6 & 8.6 & 7.6 & 9.5 & 9.0 \\
\hline Five & 3.9 & 1.8 & 1.0 & 1.1 & 1.4 & 1.9 & 1.3 & 4.0 & 3.0 & 2.9 & 1.2 & 1.3 & 1.7 & 3.1 \\
\hline Six & 5.2 & 0.9 & 0.9 & 1.0 & 0.8 & 0.4 & 0.5 & 1.6 & 1.2 & 1.1 & 0.6 & 0.4 & 0.3 & 1.6 \\
\hline Seven + & 1.2 & 0.6 & 0.6 & 0.4 & 0.2 & 0.6 & 0.4 & 2.0 & 0.7 & 0.4 & 0.5 & 0.3 & 0.3 & 0.9 \\
\hline Mean & 3.04 & 2.63 & 2.58 & 2.44 & 2.49 & 2.58 & 2.60 & 2.87 & 2.64 & 2.56 & 2.44 & 2.46 & 2.51 & 2.61 \\
\hline $\mathrm{SD}$ & 1.23 & 1.0 & .92 & .90 & .86 & .91 & .90 & 1.21 & 1.08 & .96 & .91 & .83 & .85 & 1.05 \\
\hline $\mathrm{N}$ & 649 & 1377 & 1444 & 1780 & 1348 & 1451 & 669 & 645 & 1078 & 1115 & 1358 & 1152 & 1254 & 542 \\
\hline
\end{tabular}


B. International Social Science Project (ISSP)

\begin{tabular}{cccc|ccc} 
& \multicolumn{3}{c}{ Women } & \multicolumn{3}{c}{ Men } \\
$\begin{array}{c}\text { Ideal Number } \\
\text { of Children }\end{array}$ & 1988 & 1994 & 2012 & 1988 & 1994 & 2012 \\
\hline & & & & & & \\
None & 1.0 & 0.4 & 1.2 & 1.1 & 1.0 & 1.2 \\
One & 1.7 & 2.0 & 2.1 & 1.6 & 3.9 & 3.8 \\
Two & 56.9 & 61.7 & 57.1 & 55.0 & 59.3 & 50.3 \\
Three & 22.2 & 21.4 & 27.5 & 26.2 & 21.8 & 31.6 \\
Four & 14.7 & 13.4 & 9.6 & 11.1 & 11.1 & 9.8 \\
Five & 1.8 & 1.0 & 1.9 & 2.8 & 1.9 & 1.7 \\
Six & 0.8 & 0.2 & 0.5 & 1.3 & 0.9 & 1.6 \\
Seven + & 0.8 & 0.0 & 0.2 & 0.8 & 0.2 & 0.2 \\
& & & & & & \\
Mean & 2.61 & 2.49 & 2.51 & 2.62 & 2.48 & 2.57 \\
SD & .97 & .79 & .87 & 1.03 & .94 & .95 \\
$\mathrm{~N}$ & 690 & 726 & 586 & 514 & 492 & 500 \\
\hline
\end{tabular}


Table 5. Distributions of Attitudes Towards Divorce and Durability of Marriage ${ }^{a}$

A. Monitoring the Future (MTF)

\begin{tabular}{lccccc|ccccc} 
& \multicolumn{4}{c}{ Women } & \multicolumn{1}{c}{ Men } \\
& $76-77$ & $86-87$ & $96-97$ & $06-07$ & $16-17$ & $76-77$ & $86-87$ & $96-97$ & $06-07$ & $16-17$ \\
\hline Likely Stay Married & & & & & & & & & & \\
$\quad$ (Very Likely) & 65.8 & 64.4 & 63.1 & 62.6 & 61.0 & 56.7 & $53.3 *$ & $57.3 *$ & 57.2 & 53.8 \\
$\mathrm{~N}$ & 3423 & 3073 & 2368 & 2271 & 1847 & 3290 & 2925 & 2203 & 2114 & 1871 \\
\hline
\end{tabular}

B. Intergenerational Panel Study of Parents and Children (IPS - Percent approving of divorce)

\begin{tabular}{llllll|lll|lll} 
& \multicolumn{4}{c}{ Mothers } & \multicolumn{4}{c}{ Daughters } & \multicolumn{4}{c}{ Sons } \\
& 1962 & 1977 & 1980 & 1985 & 1993 & 1980 & 1985 & 1993 & 1980 & 1985 & 1993 \\
\hline Not Stay Together & 51.1 & $80.4^{*}$ & 81.9 & 82.1 & 82.7 & 82.6 & $90.2^{*}$ & 90.2 & 66.2 & $70.2 *$ & 73.0 \\
Divorce Best & ---- & --- & 61.7 & 61.1 & 60.1 & 33.6 & 33.6 & $41.2^{*}$ & 32.4 & 32.7 & $39.8^{*}$ \\
$\mathrm{~N}$ & 801 & 801 & 801 & 801 & 801 & 408 & 408 & 408 & 393 & 393 & 393 \\
\hline
\end{tabular}

C. International Social Science Project (ISSP)

\begin{tabular}{lllll|lllll}
\multicolumn{9}{c}{ Women } & \multicolumn{5}{c}{ Men } \\
& 1988 & 1994 & 2002 & 2012 & 1988 & 1994 & 2002 & 2012 \\
\hline & & & & & & & & \\
Divorce Best & --- & 46.6 & $37.9^{*}$ & $49.0^{*}$ & --- & 49.0 & $43.4^{*}$ & $53.4^{*}$ \\
$\mathrm{~N}$ & & 789 & 616 & 646 & & 541 & 448 & 540 \\
\hline
\end{tabular}

* Asterisks indicate that the difference between that year and the earlier year is statistically significant at the .05 level. See Table 1 for statistical significance tests used.

a The question wording and coding of responses are provided in the appendix. 
Table 6. Distribution of Attitudes Toward Premarital Sex ${ }^{a}$

A. General Social Survey (GSS - Percent disapproving)

\begin{tabular}{|c|c|c|c|c|c|c|c|c|c|c|c|c|}
\hline & \multirow[b]{2}{*}{$74 / 75$} & \multirow[b]{2}{*}{$85-86$} & \multicolumn{3}{|c|}{ Women } & \multicolumn{6}{|c|}{ Men } & \multirow[b]{2}{*}{2018} \\
\hline & & & $96 / 98$ & $04 / 06$ & $14 / 16$ & 2018 & $74 / 75$ & $85-86$ & $96 / 98$ & $04 / 06$ & $14 / 16$ & \\
\hline $\begin{array}{l}\text { Premarital Sex } \\
\text { (Wrong only } \\
\text { sometimes or } \\
\text { not at all) }\end{array}$ & 45.2 & $53.6^{*}$ & $57.8^{*}$ & 58.7 & $70.7^{*}$ & 73.2 & 54.4 & $65.2 *$ & 68.1 & 67.4 & $76.5^{*}$ & 77.2 \\
\hline $\mathrm{N}$ & 1422 & 1544 & 2005 & 1398 & 1745 & 765 & 1188 & 1195 & 1531 & 1143 & 1430 & 623 \\
\hline $\begin{array}{l}\text { Teen Sex } \\
\text { (Wrong only } \\
\text { sometimes or } \\
\text { not at all) }\end{array}$ & ---- & 9.0 & 9.0 & 10.0 & $17.8^{*}$ & $21.9 *$ & ---- & 15.8 & 15.0 & 13.5 & $21.2 *$ & $27.6^{*}$ \\
\hline $\mathrm{N}$ & ---- & 777 & 2008 & 1408 & 1756 & 770 & ---- & 574 & 1529 & 1145 & 1433 & 624 \\
\hline
\end{tabular}

* Asterisks indicate that the difference between that year and the earlier year is statistically significant at the .05 level. See Table 1 for statistical significance tests used.

a The question wording and coding of responses are provided in the appendix.

b The question concerning Teen Sex was not asked in the 1985 GSS data collection so only 1986 data were used. 
Table 7. Distribution of Attitudes Toward Extramarital Sex and the Restrictivity of Exclusive Relationships ${ }^{a}$

A. General Social Survey (GSS )

\begin{tabular}{lcccccc|cccccc}
\multicolumn{1}{c}{ Women } & \multicolumn{1}{c}{ Men } \\
\hline & $76-77$ & $84-85$ & $96 / 98$ & $04 / 06$ & $14 / 16$ & 2018 & $76-77$ & $84-85$ & $96 / 98$ & $04 / 06$ & $14 / 16$ & 2018 \\
Extramarital Sex & & & & & & & & & & & & \\
$\quad$ Always Wrong & 76.1 & 76.6 & 80.6 & 84.3 & 80.0 & 77.5 & 68.0 & 69.6 & 75.0 & 77.4 & 3.8 & 71.9 \\
$\quad$ Almost Always Wrong & 12.2 & 15.2 & 12.3 & 9.8 & 11.5 & 11.6 & 16.4 & 14.8 & 14.2 & 14.4 & 15.0 & 16.8 \\
$\mathrm{~N}$ & 1481 & 1551 & 1992 & 1430 & 1781 & 778 & 1193 & 1138 & 1513 & 1089 & 1440 & 605 \\
\hline
\end{tabular}

B. Monitoring the Future (MTF - Percent Disagreeing)

\begin{tabular}{lccccc|ccccc} 
& \multicolumn{9}{c}{ Women } & \multicolumn{7}{c}{ Men } \\
& $76-77$ & $86-87$ & $96-97$ & $06-07$ & $16-17$ & $76-77$ & $86-87$ & $96-97$ & $06-07$ & $16-17$ \\
\hline & & & & & & & & & & \\
$\begin{array}{l}\text { One Partner Too Restrictive } \\
\text { (Disagree) }\end{array}$ & 65.5 & $71.9 *$ & $75.1^{*}$ & 72.3 & 69.3 & 53.2 & $59.1 *$ & $62.5^{*}$ & 62.0 & 61.8 \\
$\mathrm{~N}$ & 3423 & 3213 & 2366 & 2205 & 1653 & 3290 & 3018 & 2220 & 1931 & 2010 \\
\hline
\end{tabular}

* Asterisks indicate that the difference between that year and the earlier year is statistically significant at the.05 level. See Table 1 for statistical significance tests used.

a The question working and coding of responses are provided in the appendix. 
Table 8. Attitudes Towards Cohabitation Without Marriage ${ }^{a}$

A. Intergenerational Panel Study of Parents and Children (IPS - Percent Approving)

\begin{tabular}{lccc|ccc|cccc} 
& \multicolumn{3}{c}{ Mothers } & \multicolumn{3}{c}{ Daughters } & \multicolumn{3}{c}{ Sons } \\
& 1980 & 1985 & 1993 & 1980 & 1985 & 1993 & 1980 & 1985 & 1993 \\
\hline & & & & & & & & & \\
Live Together Alright & 23.0 & $26.8^{*}$ & $32.6^{*}$ & 44.4 & $56.6^{*}$ & $64.2^{*}$ & 59.4 & $69.4^{*}$ & 71.8 \\
Should Not Live Together & 26.1 & $35.8^{*}$ & 36.0 & 58.2 & $68.9^{*}$ & 73.8 & 71.6 & $79.0^{*}$ & 78.1 \\
$\mathrm{~N}$ & 801 & 801 & 801 & 408 & 408 & 408 & 393 & 393 & 393 \\
\hline
\end{tabular}

B. Monitoring the Future (MTF - Percent Agreeing)

\begin{tabular}{|c|c|c|c|c|c|c|c|c|c|c|}
\hline & \multicolumn{5}{|c|}{ Women } & \multicolumn{4}{|c|}{ Men } & \multirow[b]{2}{*}{$16-17$} \\
\hline & $\begin{array}{l}76- \\
77\end{array}$ & $86-87$ & $96-97$ & $06-07$ & $16-17$ & $76-77$ & $86-87$ & $96-97$ & 06-07 & \\
\hline Live Together Good Idea & 33.0 & $42.8^{*}$ & $58.9 *$ & $61.1 *$ & $69.5 *$ & 46.9 & $56.8 *$ & $66.8 *$ & 65.5 & $73.4^{*}$ \\
\hline $\mathrm{N}$ & 3423 & 3221 & 2370 & 2212 & 1663 & 3290 & 3025 & 2170 & 1941 & 1559 \\
\hline
\end{tabular}

C. Monitoring the Future (MTF)

\begin{tabular}{lccccc|cccccc} 
& \multicolumn{9}{c}{ Women } & \multicolumn{1}{c}{ Men } \\
& $76-77$ & $86-87$ & $96-97$ & $06-07$ & $16-17$ & $76-77$ & $86-87$ & $96-97$ & $06-07$ & $16-17$ \\
\hline & & & & & & & & & & \\
Morality of Cohabitation & & & & & & & & & & \\
Worthwhile Experiment & 18.7 & 24.7 & 18.2 & --- & --- & 20.5 & 24.8 & 18.6 & --- & --- \\
$\quad \begin{array}{l}\text { Doing Own Thing } \\
\text { Destructive to Society }\end{array}$ & 50.7 & 50.9 & 58.2 & --- & --- & 54.3 & 50.4 & 53.2 & --- & --- \\
$\quad \begin{array}{l}\text { Violating Moral } \\
\text { Principle }\end{array}$ & 16.9 & 13.8 & 12.7 & --- & --- & 08.3 & 6.1 & 6.0 & --- & --- \\
$\quad$ None of the Above & 06.5 & 6.9 & 7.4 & --- & --- & 10.7 & 10.8 & 11.9 & --- & --- \\
N & 3423 & 3006 & 2262 & & --- & 06.1 & 7.9 & 10.3 & --- & --- \\
\hline
\end{tabular}


D. International Social Science Project (ISSP - Percent Agreeing)

\begin{tabular}{lcccc|cccl} 
& \multicolumn{9}{c}{ Women } & \multicolumn{5}{c}{ Men } \\
& 1988 & 1994 & 2002 & 2012 & 1988 & 1994 & 2002 & 2012 \\
\hline & & & & & & & & \\
Live Together All Right & --- & 36.1 & $41.9^{*}$ & $49.5^{*}$ & & 43.3 & 46.9 & $57.6^{*}$ \\
Live Together Good Idea & --- & 24.5 & $40.7^{*}$ & --- & -- & 37.9 & $50.1^{*}$ & --- \\
$\mathrm{N}$ & & 789 & 616 & 647 & & 540 & 448 & 539 \\
\hline
\end{tabular}

* Asterisks indicate that the difference between that year and the earlier year is statistically significant at the .05 level. See Table 1 for statistical significance tests used.

a The question wording and coding of responses are provided in the appendix. 
Table 9. Attitudes Toward Nonmarital Childbearing and Childrearinga

\section{A. Monitoring the Future (MTF)}

\begin{tabular}{lccccc|ccccc} 
& \multicolumn{9}{c}{ Women } & \multicolumn{7}{c}{ Men } \\
& $76-77$ & $86-87$ & $96-97$ & $06-07$ & $16-17$ & $76-77$ & $86-87$ & $96-97$ & $06-07$ & $16-17$ \\
\hline Morality of Unmarried & & & & & & & & & \\
Childbearing & & & & & & & & & \\
Worthwhile Experiment & 7.8 & 8.6 & 8.9 & --- & --- & 10.1 & 9.2 & 8.0 & --- & --- \\
$\quad$ Doing Own Thing & 29.3 & 38.0 & 46.2 & --- & --- & 36.4 & 37.8 & 41.6 & --- & --- \\
Destructive to Society & 23.1 & 17.6 & 14.8 & --- & --- & 30.2 & 17.2 & 19.0 & --- & --- \\
$\quad$ Violating Moral Principle & 24.6 & 22.9 & 17.4 & --- & --- & 21.2 & 23.7 & 18.6 & --- & -- \\
$\quad$ None of the Above & 15.2 & 12.9 & 12.7 & --- & --- & 12.0 & 12.1 & 12.8 & --- & --- \\
N & 3423 & 2992 & 2254 & & & 3290 & 2664 & 1980 & & \\
\hline
\end{tabular}

\section{B. International Social Science Project (ISSP)}

\begin{tabular}{lcccc|cccc} 
& \multicolumn{1}{c}{ Women } & \multicolumn{1}{c}{ Men } \\
\hline & 1988 & 1994 & 2002 & 2012 & 1988 & 1994 & 2002 & 2012 \\
\hline & & & & & & & & \\
Marriage and Children & & & & & & & & \\
Strongly Agree/ Agree & 74.2 & 72.7 & 61.4 & 56.9 & 77.8 & 74.6 & 69.9 & 66.1 \\
$\quad$ Neither & 11.8 & 10.0 & 15.7 & 19.6 & 10.8 & 11.1 & 16.8 & 19.2 \\
Disagree/ Disagree Strongly & 14.0 & $17.3^{*}$ & $23.0^{*}$ & 23.5 & 11.6 & 14.2 & 13.2 & 14.7 \\
N & 717 & 786 & 615 & 648 & 533 & 540 & 448 & 540 \\
& & & & & & & & \\
One Parent Upbringing as Good as Two & & & & & & & & \\
Agree/Strongly Agree & --- & 41.6 & $48.3 *$ & $56.8^{*}$ & --- & 23.8 & $28.1^{*}$ & $33.1^{*}$ \\
Neither & & 14.1 & 12.8 & 11.3 & & 17.3 & 15.1 & 10.4 \\
Disagree/Strongly Disagree & & 44.3 & 38.9 & 32.0 & & 58.8 & 56.8 & 56.5 \\
N & & 789 & 616 & 648 & & 541 & 448 & 540 \\
\hline
\end{tabular}

* Asterisks indicate that the difference between that year and the earlier year is statistically significant at the .05 level. See Table 1 for statistical significance tests used.

a The question wording and coding of responses are provided in the appendix. 
Table 10. Attitudes Toward Same-Sex Relations and Marriage

\section{A. General Social Survey (GSS)}

Women Men

\begin{tabular}{|c|c|c|c|c|c|c|c|c|c|c|c|c|}
\hline & $76-77$ & $84-85$ & $94 / 96$ & $04 / 06$ & $14 / 16$ & 2018 & $76-77$ & $84-85$ & $94 / 96$ & $04 / 06$ & $14 / 16$ & 2018 \\
\hline $\begin{array}{l}\text { Sexual Relations Same } \\
\text { Sex Partners } \\
\text { (wrong only sometimes } \\
\text { or not wrong at all) }\end{array}$ & 18.7 & 18.4 & $29.3 *$ & $39.7 *$ & $56.8^{*}$ & $65.2 *$ & 20.7 & 19.4 & $26.7^{*}$ & $34.8^{*}$ & $53.2 *$ & 57.1 \\
\hline $\begin{array}{l}\text { Homosexual give } \\
\text { speech in community } \\
(\text { allow) }\end{array}$ & 58.6 & $66.6^{*}$ & $80.1 *$ & 81.6 & $88.8 *$ & 88.7 & 63.8 & $68.2 *$ & $79.5^{*}$ & $84.4^{*}$ & $90.1 *$ & 88.8 \\
\hline $\begin{array}{l}\text { Homosexual teach in } \\
\text { college/university } \\
(\text { allow })\end{array}$ & 46.9 & $56.3 *$ & $73.6^{*}$ & $79.4 *$ & $88.2^{*}$ & 88.8 & 52.1 & $56.6^{*}$ & $70.5^{*}$ & $79.3 *$ & $87.6^{*}$ & 85.9 \\
\hline $\begin{array}{l}\text { Pro-homosexuality book } \\
\text { in library } \\
\text { (do not remove) }\end{array}$ & 51.2 & $55.9 *$ & $69.1 *$ & $74.8 *$ & $81.5^{*}$ & $85.0 *$ & 57.0 & 58.9 & $67.9 *$ & $75.0 *$ & $82.0 *$ & 83.2 \\
\hline $\begin{array}{l}\text { Homosexuals right to } \\
\text { marry (agree) }\end{array}$ & --- & --- & --- & 35.6 & $58.6^{*}$ & $70.7 *$ & --- & --- & --- & 27.8 & $56.4^{*}$ & $62.1 *$ \\
\hline $\mathrm{N}$ & 1490 & 1556 & 2035 & 1623 & 1799 & 789 & 1197 & 1138 & 1597 & 1226 & 1454 & 615 \\
\hline
\end{tabular}

B. International Social Science Project (ISSP)

\begin{tabular}{lll|rl} 
& \multicolumn{2}{c}{ Women } & \multicolumn{2}{c}{ Men } \\
\hline & 1988 & 2012 & 1988 & 2012 \\
& & & & \\
Homosexuals should have right to marry (agree) & 12.2 & $51.6^{*}$ & 9.3 & $41.5^{*}$ \\
$\mathrm{~N}$ & 717 & 674 & 532 & 531 \\
\hline
\end{tabular}




\section{Online Appendix B: Wording, Response Categories, and Coding for All Items}

\section{Table 1. Percentage of Respondents with Egalitarian Gender Attitudes}

The question wording for each item is listed below with the response codes in parentheses. The codes in italics were treated as egalitarian in this analysis.

\section{Intergenerational Panel Study of Parents and Children (IPS)}

Decisions: Most of the important decisions in the life of the family should be made by the man of the house (Strongly Agree "SA"; Agree "A"; Undecided, Don't Know, Depends "DK"; Disagree "D"; Strongly Disagree "SD").

Women Active: It's perfectly alright for women to be very active in clubs, politics, and other outside activities before the children are grown up $(S A ; A ; \mathrm{DK}$; D; $\mathrm{SD})$.

Men's/Women's Work: There is some work that is men's and some that is women's, and they should not be doing each others (SA; A; DK; $D ; S D)$.

Housework: A wife should not expect her husband to help around the house after he comes home from a hard days work (SA; A; DK; D; SD).

Relations/Working Mother: A working mother can establish as warm and secure a relationship with her children as a mother who does not work $(S A ; A ; \mathrm{DK} ; \mathrm{D} ; \mathrm{SD})$.

Men Work/Women Home: It is much better for everyone if the man earns the main living and the woman takes care of the home and the family (SA; A; DK; $D ; S D)$.

Women Happier Home: Women are much happier if they stay at home and take care of their children (SA; A; DK; D; SD).

Husband/Wife Career: It is more important for a wife to help her husband's career than to have one herself (SA; A; DK; D; SD).

\section{Monitoring the Future (MTF)}

Decisions: The husband should make all the important decisions in the family (Disagree " $D$ "; Mostly Disagree "MD"; Neither "N"; Mostly Agree "MA"; Agree "A").

Housework: If a wife works, her husband should take a greater part in housework and childcare $(\mathrm{D} ; \mathrm{MD} ; \mathrm{N} ; M A ; A)$. 
Relations/Working Mother: A working mother can establish just as warm and secure a relationship with her children as a mother who does not work (D; MD; N;MA;A).

Preschool Child Suffer: A preschool child is likely to suffer if the mother works $(D ; M D ; \mathrm{N}$; MA; A).

Men Achieve/Women Home: It is usually better for everyone involved if the man is the achiever outside the home and the woman takes care of the home and family $(D ; M D ; \mathrm{N} ; \mathrm{MA}$; A).

Job \& Relations with Husband: Having a job takes away from a woman's relationship with her husband $(D ; M D ; \mathrm{N} ; \mathrm{MA} ; \mathrm{A})$.

Job Allows Wife Development: Having a job gives a wife more of a chance to develop herself as a person. $(\mathrm{D} ; \mathrm{MD} ; \mathrm{N} ; M A ; A)$.

\section{General Social Survey (GSS)}

Relations/Working Mother: A working mother can establish just as warm and secure a relationship with her children as a mother who does not work $(S A ; A ; \mathrm{DK} ; \mathrm{D} ; \mathrm{SD})$.

Husband/Wife Career: It is more important for a wife to help her husband's career than to have one herself. (SA; A; DK; D; SD).

Preschool Child Suffer: A preschool child is likely to suffer if his or her mother works (SA; A; $\mathrm{DK} ; D ; S D)$.

Men Achieve/Women Home: It is much better for everyone involved if the man is the achiever outside the home and the woman takes care of the home and family (SA; A; DK; $D ; S D)$.

Married Women Work: Do you approve or disapprove of a married woman earning money in business or industry if she has a husband capable of supporting her (Approve; Disapprove; Don't Know)?

\section{International Social Science Program (ISSP)}

Relations/Working Mother: A working mother can establish just as warm and secure a relationship with her children as a mother who does not work (SA;A; N, DK; D; SD).

Preschool Child Suffer: A pre-school child is likely to suffer if his or her mother works (SA; A; $\mathrm{N} ; \mathrm{DK} ; D ; S D)$.

Family Life Suffers: All in all, family life suffers when the woman has a full-time job (SA; A; $\mathrm{N} ; \mathrm{DK} ; D ; S D)$. 


\section{Table 2. Distributions of Attitudes Toward Marriage}

The question wording for each item is listed below with the response codes in parentheses. For the variables that were dichotomized the response codes in italics indicate the percentage agreeing or disagreeing as noted in the variable label.

\section{Intergenerational Panel Study of Parents and Children (IPS)}

Married Happier (Disagree): Married people are usually happier than those who go through life without getting married (Strongly Agree "SA"; Agree "A"; Disagree "D"; Strongly Disagree "SD").

Few Good Marriages (Agree): There are few good or happy marriages these days (SA; $A$; D; $\mathrm{SD})$.

Better Married (Disagree): It's better for a person to get married than to go through life being single (SA; A; $D ; S D)$.

Better Single (Agree): All in all, there are more advantages to being single than to being married $(S A ; A ; \mathrm{D} ; \mathrm{SD})$.

\section{International Social Science Program (ISSP)}

Married Happier (Disagree): Married people are generally happier than unmarried people (Strongly Agree; Agree; Neither agree or disagree; Can't choose; Disagree; Strongly Disagree)

\section{Monitoring the Future (MTF)}

Married Happier (Disagree): Most people will live fuller and happier lives if they choose legal marriage rather than staying single or just living with someone (Disagree "D"; Mostly Disagree "MD"; Neither "N"; Mostly Agree "MA"; Agree "A").

Few Good Marriages (Agree): One sees so few good or happy marriages that one questions it as a way of life $(\mathrm{D} ; \mathrm{MD} ; \mathrm{N} ; M A ; A)$.

Importance Good Marriage: How important is each of the following to you in your life? Having a good marriage and family life. (Extremely important, Quite important, Somewhat important, Not important).

Choice About Marriage: Which do you think you are most likely to choose in the long run? (Response codes are the same as listed in table) 
Ideal Time to Marry: If it were just up to you, what would be the ideal time for you to get married? (Within the next year or so, 2-3 years from now, 4-5 years from now, Over 5 years from now, I don't want to marry).

\section{Table 3. Distributions of Attitudes Toward Childbearing and Parenthood}

The question wording for each item is listed below. The response categories are exactly as shown in table unless indicated otherwise.

\section{Intergenerational Panel Study of Parents and Children (IPS)}

All Couples Parents: Do you feel almost all married couples who can ought to have children?

\section{International Social Science Project (ISSP)}

Empty Lives: People who have never had children lead empty lives (Strongly Agree/Agree; Neither; Disagree/Strongly Disagree).

Children Purpose Marriage: The main purpose of marriage these days is to have children (Strongly Agree/Agree; Neither; Disagree/Strongly Disagree).

Kids No Freedom: Having children interferes too much with the freedom of the parents (Strongly Agree/Agree; Neither; Disagree/Strongly Disagree).

\section{Monitoring the Future (MTF)}

Fatherhood Fulfilling: Being a father and raising children is one of the most fulfilling experiences a man can have. (Disagree; Mostly Disagree; Neither; Mostly Agree; Agree).

Motherhood Fulfilling: Being a mother and raising children is one of the most fulfilling experiences a woman can have. (Disagree; Mostly Disagree; Neither; Mostly Agree; Agree).

Likely Want Children: How likely is it that you would want to have children? (Very likely; fairly likely; uncertain; fairly unlikely; very unlikely). 


\section{Table 4. Distributions of Attitudes Toward Ideal Number of Children}

The question wordings are listed below and codes are shown on the tables.

\section{$\underline{\text { General Social Survey (GSS) }}$}

What do you think is the ideal number of children for a family to have? (Codes same as shown on table)

International Social Science Project (ISSP)

All in all, what do you think is the ideal number of children for a family to have? (Codes same as shown on table)

\section{Table 5. Distributions of Attitudes Toward the Durability of Marriage}

The question wording for each item is listed below with the response codes in parentheses. The codes in italics were treated as approving in this analysis.

\section{Monitoring the Future (MTF)}

Likely Stay Married: If you did get married (or are married)... How likely do you think it is that you would stay married to the same person for life? (Very likely, Fairly likely, Uncertain, Fairly unlikely, Very unlikely).

\section{Intergenerational Panel Study of Parents and Children (IPS)}

Not stay together: When there are children in the family, parents should stay together even if they don't get along (Strongly Agree "SA"; Agree "A"; Don't Know "DK"; Disagree "D"; Strongly Disagree "SD").

Divorce Best: Divorce is usually the best solution when a couple can't seem to work out their marriage problems (SA; A; DK; D; SD).

\section{$\underline{\text { International Social Science Program (ISSP) }}$}

Divorce Best: Divorce is usually the best solution when a couple can't seem to work out their marriage problems ( $S A ; A$; DK; D; SD). 


\section{Table 6. Distributions of Attitudes Toward Premarital Sex (Percent Disapproving)}

The question wording for each item is listed below. The codes in italics were considered as disapproving in this analysis.

\section{$\underline{\text { General Social Survey (GSS) }}$}

Premarital Sex: There's been a lot of discussion about the way morals and attitudes about sex are changing in this country. If a man and woman have sex relations before marriage, do you think it is always wrong, almost always wrong, don't know, wrong only sometimes, or not wrong at all?

Teen Sex: What if they are in their early teens, say 14 to 16 years old? In that case, do you think sex relations before marriage are always wrong, almost always wrong, don't know, wrong only sometimes, or not wrong at all?

\section{Table 7. Distributions of Attitudes Toward Extramarital Sex and Exclusive Relationships}

The question wording for and response categories for each item are listed below.

\section{General Social Survey (GSS)}

Extramarital Sex: What is your opinion about a married person having sexual relations with someone other than the marriage partner? (Always wrong, Almost always wrong, Wrong only sometimes, Not wrong at all, Don't know)

\section{Monitoring the Future (MTF)}

One Partner Too Restrictive: Having a close intimate relationship with only one person is too restrictive for the average person (Disagree, Mostly Disagree, Neither, Mostly Agree, Agree). 


\section{Table 8. Attitudes Toward Cohabitation Without Marriage}

The question wording for each item is listed below with response codes in parentheses. The codes in italics were considered as approving in this analysis.

\section{Intergenerational Panel Study of Parents and Children (IPS)}

Live Together Alright: It's alright for a couple to live together without planning to get married (Strongly Agree "SA"; Agree "A"; Don't Know "DK"; Disagree "D"; Strongly Disagree "SD").

Should Not Live Together: A young couple should not live together unless they are married (SA; A; DK; $D ; S D)$.

\section{Monitoring the Future (MTF)}

Live Together Good Idea: It is usually a good idea for a couple to live together before getting married in order to find out whether they really get along (Disagree; Mostly Disagree; Neither; Mostly Agree; Agree).

Morality of Cohabitation: A man and a woman who live together without being married are...(Experimenting with a worthwhile alternative lifestyle; Doing their own thing and not affecting anyone else; Living in a way that could be destructive to society; Violating a basic principle of human morality; None of the above).

\section{$\underline{\text { International Social Science Program (ISSP) }}$}

It is alright for a couple to live together without intending to get married (SA;A; DK; D; SD).

It's a good idea for a couple who intend to get married to live together first (SA;A; DK; D; SD). 


\section{Table 9. Attitudes Toward Unmarried Childbearing}

\section{Monitoring the Future (MTF)}

Morality of unmarried childbearing: A man and a woman who decide to have and raise a child out of wedlock are... Experimenting with a worthwhile alternative lifestyle; Doing their own thing and not affecting anyone else; Living in a way that could be destructive to society; Violating a basic principle of human morality; None of the above.

\section{$\underline{\text { International Social Science Project }}$}

Marriage and children: People who want children ought to get married. Strongly Agree, Agree, Neither/Don’t Know, Disagree, Strongly Disagree.

One parent upbringing: One parent can bring up a child as well as two parents together. Strongly Agree, Agree, Neither/Don't Know, Disagree, Strongly Disagree.

\section{Table 10. Attitudes Towards Same-Sex Relations and Marriage}

\section{General Social Survey (GSS)}

What about sexual relations between two adults of the same sex--do you think it is always wrong, almost always wrong, wrong only sometimes, or not wrong at all?

And what about a man who admits that he is a homosexual?

A. Suppose this admitted homosexual wanted to make a speech in your community. Should he be allowed to speak, or not? (Allowed; Not Allowed; Don't Know)

B. Should such a person be allowed to teach in a college or university, or not? (Allowed; Not Allowed; Don't Know)

C. If some people in your community suggested that a book he wrote in favor of homosexuality should be taken out of your public library, would you favor removing this book, or not?

(Remove; Not Remove; DK)

Homosexual couples should have the right to marry one another (Strongly Agree/Agree; Neither; Disagree/Strongly Disagree).

\section{International Social Science Project (ISSP)}

Homosexual couples should have the right to marry one another (Strongly Agree/Agree; Neither; Disagree/Strongly Disagree). 


\section{Online Appendix C: Monitoring the Future (MTF) Changes Across Waves}

\section{1) Geographic Coverage}

In response to California state requirements, the MTF study was required to omit several attitudinal measures from the questionnaires distributed amongst California high school seniors from 1997 onwards. Five of those measures pertained to long-term trends reported in this paper, as well as in our two previous publications. Since these measures continued to be asked of high schoolers in all other parts of the country, we were reluctant to drop them, but recognized reporting post-1996 trends without including California might lead to misleading results. To mitigate this concern, we analyzed data collected in the two years prior to the first interval where this problem might occur, (1996/1997), separately for males and females. We ran the analysis first using every observation collected in 1994 and 1995, and then repeated it dropping cases that had been collected from high schools in the western region of the U.S. Results were virtually identical between the two geographical definitions across all five measures for both males and females.

Specific measures omitted in California (in order of appearance on the tables) are:

Table 1. The husband should make all the important decisions in the family

Table 2. Most people will live fuller and happier lives if they choose legal marriage rather than staying single or just living with someone

Table 2. One sees so few good or happy marriages that one questions it as a way of life Table 7. Having a close intimate relationship with only one person is too restrictive for the average person

Table 8. It is usually a good idea for a couple to live together before getting married in order to find out whether they really get along 


\section{2) Motherhood Item Placement}

Data for two MTF trends, "Being a mother and raising children is one of the most fulfilling experiences a woman can have" and "Being a father and raising children is one of the most fulfilling experiences a man can have" require explanation. From 1976-2000, the motherhood item appeared just on Form 5, and the fatherhood item appeared just on Form 4. In the intervals we report for this time period, the proportion of males mostly agreeing or agreeing that "fatherhood is one of the most fulfilling experiences a man can have" is about $20 \%$ higher than it is for males answering the corresponding question about motherhood on Form 5. Females during the same time period tend to report roughly the same levels of agreement concerning parental fulfillment, regardless of whether they were asked about mothers or fathers.

Beginning in 2001, the motherhood item was added to Form 4, directly following the fatherhood question. This addition meant we could now analyze "motherhood fulfilling" attitudes for about twice as many MTF respondents. When we did that for our post-2001 intervals we noticed a substantial increase in agreement (15\%) for "motherhood fulfilling" coming from our male respondents. We reran the analysis, omitting "motherhood fulfilling" responses originating from Form 4, and the male trends reverted back to levels similar to those reported in intervals prior to 2001. We suspect the Form 4 addition and placement of the motherhood question (immediately following the fatherhood question) may have inadvertently created a method effect on male responses relative to the motherhood variable, but further analyses is needed to test that hypothesis adequately. Since investigating method effects are outside the scope of this research, the post-2001 analyses we present are performed identically to those from the prior intervals - motherhood attitudes calculated from Form 5 responses, and fatherhood attitudes calculated from Form 4 responses. 